\title{
Performing Authorship in the Music of Contemporary Singer-Songwriters
}

\author{
Ailsa Lipscombe
}

\begin{abstract}
A Thesis submitted to Massey University and Victoria University of Wellington in partial fulfillment of the requirements for the degree of Master of Music in Musicology
\end{abstract}

New Zealand School of Music

March 2015 
(C) Copyright by Ailsa Lipscombe

All rights reserved

March 2015 


\begin{abstract}
Performing Authorship in the Music of Contemporary Singer-Songwriters
\end{abstract}

\author{
Ailsa Lipscombe \\ (Under the supervision of David Cosper \\ and Kimberly Cannady)
}

This thesis explores the dynamic and oftentimes puzzling relationship between singer, song, and listener in the music of contemporary singer-songwriters. I argue that this relationship is simultaneously understood through and confused by the use of indeterminate pronouns in song lyrics. The crossing over of language from speech to song leads to a multiplicity of "readings" of music and artists, where the "I" of the song's narrator is elided with the "I" of the composer and the "I" of the performer. In this research I highlight the importance of listener experience in the ways these "I"s are contextualized and examined, shedding light on the dynamic and varied ways listeners are already engaging with this music. I also explore how these understandings ultimately impact listeners' broader perceptions of the often-gendered values of emotional honesty and truthfulness of singer-songwriters.

This research brings together original ethnographic research and theoretical explorations of musical and literary authorship and interpretation, focusing on the creative work of three singer-songwriters - Amanda Palmer, Hera Hjartardóttir, and Katie Morton. By drawing on these diverse research areas and musical repertoires, I propose an interdisciplinary model that highlights the active role listeners play in the creation (or discovery) of musical meaning. My hope is that this thesis opens up a space for future discussions to take place that examine the many layers of live performance that impact and inform interpretations of narrative, while also giving a voice to the listeners and fans whose engagement forms a crucial element of these singer-songwriter performances. 



\section{Acknowledgments}

Completing this thesis has been an exciting and rewarding, albeit it at times hectic, journey. The years I have spent at the New Zealand School of Music have engendered in me a passion for research and teaching, and I am forever grateful for the community of scholars, colleagues, and friends that I have found there. As I embark on future journeys into academia, my work will always be laced with the honest and collaborative model of scholarship that I have been so thankful to learn during my time at NZSM.

Thanks are due to a number of faculty and friends who have supported me through this time and always offered me encouragement when I needed it most:

- to Amanda Palmer, Hera Hjartardóttir, and Katie Morton, whose music inspired me to undertake this research, and whose help and generosity made it all possible;

- to all those who participated in my e-field research, whose contributions were invaluable and whose voices I hope are justly represented across these pages;

- to my NZSM whanau, friends, and colleagues, whose wisdom and friendship have made this journey academically enriching and altogether enjoyable;

- to John, who never fails to make me the best coffee in Wellington.

In particular, special thanks:

- to Jonny Avery and Nell Thomas, who made the past year both studious and entertaining, and whose musical interludes made ours the best office on campus;

- to my anonymous reviewers, whose feedback provided plenty of encouragement and useful insights for this and future research endeavors;

- to Kim Cannady, whose continuous support and guidance I am ever grateful for, and who it has been a privilege to work alongside;

- to David Cosper, whose enthusiasm and passion inspired me to begin this journey, and whose help and encouragement have seen me through until the end.

And to my family and friends who have stuck by me and given me their constant love and care, thank you. Your support has been never-ending and always appreciated; if it weren't for the belief you showed in me, this thesis would have remained but an idea and not a reality. This one's for you. 

Dedicated to C.

- for always keeping me grounded 



\section{Table of Contents}

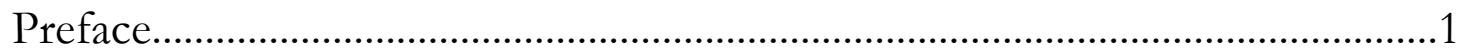

Chapters

1. What's in a Hyphen: Locating the Individual in the Singer-Songwriter.....

2. What's in an "I": Locating the Story of the Singer-Songwriter.

3. What's in a Sigh: Locating the

Voice of the Singer-Songwriter.

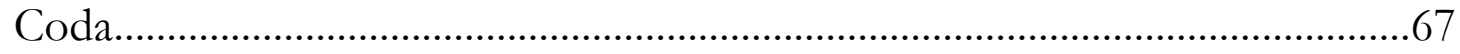

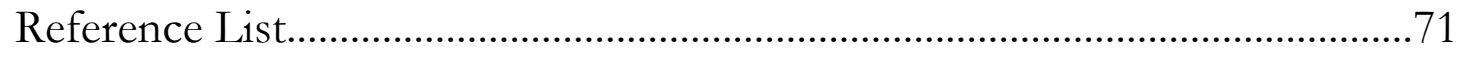





\section{Preface}

\section{I: $12^{\text {th }}$ March 2010}

WE ARRIVE three hours early. Ghuznee Street is quiet, the late afternoon traffic is flowing steadily and the few stragglers by the bar door unobtrusively occupy a small fraction of the pavement. I know that by the time Bar Bodega opens, the pavement will be teeming with eager fans, anxious to enter the building and fuel up at the bar, before rushing to get those coveted front row spots. But for now, the street is quiet.

The afternoon is surprisingly warm and I grumble under my breath about having to lug my jacket around. I hook it over my crutches, then transfer it to under my arm, then swing it over my shoulder. My sister Jessie is quick to silence my complaining by reminding me that I will be grateful to have it when the concert ends and the temperature drops.

As people start to arrive, it is clear that many of the concertgoers know one another. Hugs are exchanged; laughs are shared; stories are told. This is my first Amanda Palmer show and the only person I know here is Jessie. We stand next to each other, occasionally speaking and at other times listening to the snippets of conversation around us:

"Have you read Amanda's latest blog about this tour? Tonight's going to be amazing," a guy with outrageously bleached hair and a pierced lip exclaims.

"Do you like my outfit? I tweeted Amanda for help about what to wear," says a girl sporting a black lace corset, not unlike those worn by Amanda herself at previous shows.

“I hope that she performs 'Boston' - that's one of the most honest and raw songs I've ever heard," comments an older woman to a group of similarly aged attendees.

Eventually the bouncer comes outside and asks us to line up. The once calm atmosphere becomes charged with anxiety and anticipation as people try to get as close to the front of the queue as possible. Jessie and I are standing by the door and are joined by our mum, who hadn't been interested in queuing for hours with us. Two days before turning 18, I am legally too young to be entering this venue without parental supervision. As an early birthday present, Mum has agreed to come to the concert with us. We file in quickly, handing over our tickets and IDs. Jessie and I immediately make our way to the 
front of the stage, eager to get a good view; Mum hangs back, taking up sentry on one of the couches that occupy the rear of the bar.

The room's atmosphere becomes muggy and heavy the longer we wait. Jessie escapes through the crowd that has begun to form behind us to buy water, as the close crush of people takes its toll on us. In comparison to the crowded room, the stage itself is relatively sparse. Amanda's signature PC3X Kurzweil electric piano stands off to the right with fresh flowers winding up the legs and around the body of the instrument. ${ }^{1}$ The spotlight, already on, highlights the unoccupied space on the slightly raised stage. The emptiness speaks of promise of the evening to come, and seems to buzz with the ghosts of music played there in the past.

I sigh with relief when Amanda Palmer walks on stage an hour later to introduce the opening act, finally silencing the woman beside me who has spent the last 15 minutes bellowing, "Why are we waiting?" It is like sighting an old friend to see Amanda on the stage in front of me. However, I had never met Amanda before. Not in person, at least. For the last five years, I had "met" Amanda on numerous occasions - on Twitter, on her blog, through her music, and through her lyrics. For me, and for many others at the concert, meeting her in person is simply one of many ways we can connect with the "real" Amanda Palmer. By real I do not just mean the living, breathing woman; I also refer to the person I already felt I knew through engagement with virtual and musical practices: in the physical world, in the digital world of social media platforms, and in the aural space created when you put on a CD and immerse yourself in the world of the performer.

The evening progresses steadily following Amanda's introduction of the opening act. Hera, an Iceland-born, Christchurch-based singer, whose music I have never heard before, comes on stage, guitar in hand. She performs a quirky and fun set that enchants the crowd. We laugh at her witty banter that flows between the songs and are drawn in by the intimate storyteller quality in her music. I turn to Jessie and ask if I should buy Hera's $\mathrm{CD}$, which is available along with other merchandise at the back of the room. I'm not sure if she can hear me over the music and crowd, but she seems to get the gist of what I'm saying as she nods furiously, before turning back to the stage.

\footnotetext{
${ }^{1}$ In this opening section, all performers are referred to by their first names. This decision was made in order to preserve the informal atmosphere of the event and to illustrate the personal connections I felt with the performers. It also represents the personalized nature of the singer-songwriter genre, which will be discussed in more detail in Chapter One.
} 
Hera's set comes to an end, and with a wave and cheerful farewell, she departs the stage. The spotlight once again lights the empty floor space. Forty minutes pass and the crowd starts to get impatient; the woman behind me starts up her chanting again. Every time her fist pumps the air to stress her frustration, her arm hits my shoulder and knocks me into the people on either side of me. I turn around, intending to ask the woman to stop hitting me, but as soon as my back is to the stage I hear a giant roar from the crowd. Amanda Palmer is back.

Amanda greets the audience, addressing us as a community by referring to the room collectively as "Wellington." She launches into a story about her current tour: where she has been, what the weather has been like, what she has been inspired to write or compose or sing. The audience starts to participate with her stories, calling out interjections or responses to various things she says. I can hear voices from around the room shout out song suggestions. Bending down next to her keyboard, Amanda picks up a bunch of vegetables - carrots and celery mixed with flowers. She systematically throws them into the audience, alternating between the left and the right of the room. One carrot left in hand, she takes a bite before looking at me and handing it over. I clasp my hand around the vegetable and grin at Jessie as Amanda stands behind her electric piano and plays a sustained opening chord. She takes her hands off the piano, dramatically looking out into the audience, before she lets out an emphatic grunt that echoes around the bar. I anticipate the series of $\mathrm{D}$ minor chords that I know are about to come, with that grunt indicating that her first song will be "Astronaut: A Short History of Nearly Nothing."

Songs blur into one another, broken up by anecdotal interludes and questions from the audience. Amanda's signature raw vocality is used to weave a story through her music, sparking people around me to comment on the "realness" of her performance, and how "honest" she is, baring her soul on stage. Before I know it, the final chord is ringing out in the room, and is quickly smothered by thunderous applause that bounces off the walls and pushes through the muggy air enveloping the bar. As Amanda turns off her keyboard and heads out back, people start to trickle out the door onto the darkened street.

I bend down to pick up a flower, scattered into the audience at the start of the night and remarkably still intact. Upon pulling out my phone, I discover a text from my mum time-stamped an hour ago and saying she was going home. I walk to the bar in a post-concert daze and find my sister. At the back of the room a fellow concert-goer sits 
alone and looks as dazed as I feel. Filled with adrenaline and joy from the concert, I approach and we start chatting.

"Hey, I’m Ailsa."

"Nice to meet you, I'm Katie."2

My sister joins us and we talk about the concert, sharing our stories of how we became Amanda Palmer fans. Katie and I swap accounts of how Amanda's music has encouraged us to compose our own. As we exchange stories, we exchange cellphone numbers too.

Those still loitering at the bar become re-energized when Amanda reappears, weaving her way through the dissipating crowd before settling at the back couch with her partner, author Neil Gaiman. Within seconds people rush forward, CDs and pens in hand, disturbing the quiet oasis Katie, Jessie and I had made for ourselves. We allow people to push past us in the queue, out of courtesy or fear of accelerating our departure I am uncertain, but eventually we are at the back of the line. We continue to talk as the line slowly grows shorter, and it is close to 1:00am when we make it to the front. Katie goes first and I barely register what is said, caught up in my own head trying to decide what to say to Amanda. While I feel as if I know her, I am conscious of the fact that she has never met me before. Katie motions to my sister and me, gesturing that we should all meet by the door when we are done. We nod and Katie walks off to wait.

I move forward. I hand over my Who Killed Amanda Palmer book and smile nervously. Amanda asks what my name is and when I reply she looks up, recognition in her eyes. "Ailsa, as in the Ailsa off Twitter?” My smile gets bigger. I nod. Amanda hands me back my book, thanks me for coming out and tells me that she'll see me back on Twitter. I shuffle to the side to talk to Neil while Jessie gets her CD signed.

Smiling, we meet up with Katie and exit the bar to wait for our taxis. The everpresent Wellington wind chills our bare arms and urges us to don our jackets. Amanda comes out the backdoor while we are waiting, so we quickly get our cameras and pose for photos with her. Finally, we get into our respective taxis and Jessie and I spend the journey home reliving the evening.

\footnotetext{
${ }^{2}$ In this thesis, Katie Morton is discussed without the use of pronouns. Katie identifies as genderqueer, and as such neither 'she' nor 'he' is appropriate. Recent studies in gender show the emergence of new genderneutral pronouns, such as 'ze/hir'. However, for this research I have instead chosen to refer to Katie by name, rather than with pronouns, gendered or otherwise. For more information on the burgeoning field of gender-neutral pronouns, see: Gender Neutral Pronoun Blog. (2014, Jan 24). The Need for a Gender-Nentral Pronoun. Retrieved from http://genderneutralpronoun.wordpress.com
} 


\section{II: Echoes of Bodega Bar}

I HAD NO IDEA how significant that concert was going to be as we drove home that night. In the following weeks, I listened to Amanda Palmer's music continuously, only interrupted by periods of time spent listening to Hera's music that I had purchased after hearing her perform at Bodega. ${ }^{3}$ The conversations I overheard that night while waiting on the street and throughout the performance still echoed through my mind, suffusing my subsequent listening experiences. Questions of rawness and honesty, qualities I already associated with Amanda, became central to my understanding of her music. My aural engagement with her music had been transformed by the visual and physical realities of seeing her perform live. The raspiness I heard in her voice became the marker of her authenticity as a performer; the autobiographical stories that I now associated with certain songs after listening to her banter became the marker of her authenticity as a person. These two personae, used interchangeably by other concertgoers and fans, fuse together to create the "authentic" Amanda Palmer listeners are drawn to.

The role of first person narratives in creating this effect hung over me and I began to recognize how first person pronouns affect musical engagement, particularly in songs where the performer appears to be singing about him or herself. The feeling of connectedness that culminated at that March $12^{\text {th }}$ concert, encouraged by prior social media interactions, was strengthened through Palmer's personable and personal performance style - a style sustained through the dissemination of both spoken and sung first person narratives.

These issues started to influence my academic work undertaken at Te Kōki New Zealand School of Music. Having at the time been immersed in scholarly literature on how musical experiences could be considered analogous to narrative, I began to take note when these conversations appeared in fan discourse. Often entwined with perceptions of honesty, openness, and authenticity, dialogues on social media platforms and at concerts about Amanda Palmer and other singer-songwriters came back to this idea of the performer sharing their personal story through music, demonstrating an elision of the narrator in the song and the author of the song. From here, listener engagement in particular influenced my research: how lyrics are interpreted; how these interpretations

\footnotetext{
${ }^{3}$ In this research I refer to Hera Hjartardóttir by her first name. In Icelandic, surnames begin with your father's first name, which is followed by the suffix -dóttir meaning 'daughter of or -son meaning 'son of. It is customary in academic writing, therefore, to refer to Icelanders by their first name. For more information, see the Ministry of the Interior's official website: Ministry of the Interior. (2002, January 22). Information on Icelandic Surnames. Retrieved from http://eng.innanrikisraduneyti.is/information/nr/125
} 
influence a listener's understanding of musical meaning; how live performance and the body impart meaning that becomes entwined with lyrical meanings; how social media platforms illustrate new ways musicians and listeners engage with music and each other.

When I met Amanda Palmer, Hera Hjartardóttir and Katie Morton for the first time at Bar Bodega, I heard audience members talk of truthfulness, honesty, and rawness as markers of authenticity in fan discourse of singer-songwriters. Listening to the fans interact with each other and with the performers, and watching the musicians in turn engage with their fans, marked the start of an academic journey that has led to completing this thesis. What started with a musical example has become a theoretical exploration into musicology, narratology, and ethnography in which I consider how fans understand the seemingly distinct roles of the singer and the songwriter within the work of singersongwriters.

My Central ARgument in this thesis is that the trichotomy of singer, song, and listener provides a dynamic space for a discussion on performative authorship and (auto)biography in the music of singer-songwriters. In a discussion of Amanda Palmer, Hera Hjartardóttir, and Katie Morton, I contextualize the role of the singer-songwriter in live performance and explore a range of interpretive practices in use by fans that are fundamental to the reception of this music. Through a combination of ethnographic and theoretical approaches to interpretation and authorship, I illuminate the under-researched genre of the singer-songwriter and suggest how one can negotiate the personae that arise through a singer-songwriter's use of first person narratives.

Chapter One opens with an introduction to key literature that has informed popular music scholarship and lays the foundations of my own research. This is followed by a break-down of the discursive function of the term "singer-songwriter" and a consideration of the expectations listeners have of a performer under this title. The second chapter highlights one significant element of singer-songwriters' performances, concentrating on the presence of first-person narratives. I argue that the use of the same linguistic paradigms in first-person narrative as in autobiography elides the categories of song and singer, and leads to cursory assumptions about authorial presence in lyrics. The theoretical interfaces developed in the previous chapters leaves space for a discussion of vocality in the final chapter, where I consider the role it plays in perceptions of gender and sex, honesty and truthfulness, with reference to the repertoires of Amanda Palmer, Hera Hjartardóttir, and Katie Morton. Through this discussion, I tie first-person written 
narratives to the act of live vocal performance, and provide an example of future research avenues to which this work could lead. 


\section{Chapter One}

\section{What's in a Hyphen: Locating the Individual in the Singer-Songwriter}

\section{I: Setting the Scene}

OVER THE PAST 25 YEARS, popular music scholarship has become widely recognized as a meaningful and worthwhile academic pursuit. The outpouring of popular music literature, and subsequent academic thought, explores the issues and questions that tease, torment, terrify, and thrill those engaged with contemporary music. I find that published materials in popular music studies have historically taken one of two approaches: either focusing on a particular genre and unpacking this discussion through reference to diverse broader topics (Davis, 1995; Gracyk, 2001), or structuring the conversation around particular issues with examples from a variety of musical genres (Frith \& Goodwin, 1990; Whiteley, 1997). Both of these approaches reveal the centrality of genre to understandings of popular music, yet left out of much of this scholarship is a consideration of the genre and act of the singer-songwriter. Aside from the occasional concentrated study on singer-songwriters (Lankford Jr., 2010; Bernstein, 2004), discussions of these musicians tend to occur in less formal environments, taking place at concerts and in forums, as well as across a host of social media platforms like Twitter, Facebook, YouTube, and blogs.

Parallel to these genre-based approaches to popular music studies are those that utilize ethnographic methodologies (Cohen, 1993; Finnegan, 1989; Middleton, 1990). Ethnography aims to draw attention to human experience and, through a reflexive and critical framework, express a detailed cultural occurrence. Sociologist Laurel Richardson synthesizes the goals of ethnography into five criteria: substantive contribution, aesthetic merit, reflexivity, impact, and expression of reality (2000, 254). In this thesis, I have worked within Richardson's ethnographic framework, using participant observation and interviews to gain insights into people's experience of the singer-songwriter genre, both from a performer's perspective as well as that of a listener and a fan. To transmit this information, I have additionally presented aspects of my research through focused ethnographic writing, employing micro-level analysis of musical events in an effort to place experience at the forefront of the work I am undertaking. Through this writing I emphasize the importance of reception by consciously drawing on my own involvement 
with music, whilst also providing a space for the experiences of other listeners to be explored and considered. As such, I bring this together within a framework of theoretical models, performance analysis, and personal experience. Additionally, my engagement with these ethnographic methods has crystalized the ways fans differentiate themselves from other listeners. This has led to a distinction between "fans" and "listeners" throughout this research, where the former is a part of the latter, but the latter need not be included in the former. I conceptualize a fan as someone who is particularly invested in a certain repertoire or performer, which leads to a higher level of active engagement with musical materials, as well as a larger body of knowledge that is subsequently used to understand musical meaning and lyrics. Similarly, I identify "fanbases" or "fandoms" as groups of fans, who are defined by their high level of individual and collective participation with a particular artist or genre.

One particular study in popular music and ethnography that has influenced my work is Sara Cohen's article 'Ethnography and Popular Music Studies,' which advocates for the use of ethnographic techniques in popular music research and has encouraged me to seek answers and opinions from those most closely involved in the repertoire governing my thesis research. Cohen argues that popular music is an inherently social activity and as such should be approached through a focus on 'social relationships, emphasizing music as social practice and process' as opposed to relying only on theoretical models and decontextualized statistical data (1993, 123). This article provides a stable context for a well-grounded conversation on ethnography and popular music, and Cohen's conviction that ethnography was the missing piece in the puzzle of popular music studies has guided my thesis research. Cohen's assiduous review of the anthropological usages of ethnography and her discussion of contemporary research on popular music that could be improved through the inclusion of ethnographic techniques, has motivated me to think about various singer-songwriter experiences as sociallyconstructed realities.

For this research I utilize genre-based approaches to popular music, as well as ethnography, to elucidate listener experiences of musical "texts". Drawing on ethnographic research, musicological theories, and literary reader-response criticism, I consider the presence of listeners in the interpretation of the work of singer-songwriters, highlighting how many of the genre expectations and tropes used to understand singersongwriter "texts" are created and perpetuated through fan discourse. 


\section{II: Tuning the Vocabulary}

\section{The Discursive Function of "Singer-Songwriters"}

ONE OF THE FIRST PROBLEMS a keen music scholar or fan stumbles upon when discussing singer-songwriters is the syntactical limitations of the term itself. Whether referring to the act of writing and singing music, the artist, or the genre as a whole, the same term is used indiscriminately (Knopfler, 2003). This creates perplexity over what is in fact being referred to, and leads to confusion being masked as assured understanding. The reduction of these three distinct entities into one through the use of a singular term perpetuates a simplistic understanding of singer-songwriters that ignores the complex relationships between these different definitions of the term. Through an exploration of what is currently encompassed by the term "singer-songwriter," I hope to demonstrate that the convoluted nature of the term itself illustrates the complex and varied nature of this genre, group of musicians, and repertoire. I identify the term singer-songwriter in a variety of manifestations, ranging from being indicative of what acts are undertaken by performers to the expectations listeners have of musicians performing under this title, and the co-existence of these varied understandings highlight the shaky vocabulary this repertoire is built on.

The term "singer-songwriter" implies two separate and distinguishable functions: singing and writing. It suggests that the work undertaken by a musician in this genre can be split cleanly into two different realms, each with its own set of expectations and roles. Understanding these two areas of work as distinct creative activities that occur in a particular order (first songwriting and then singing) reduces a highly complex process and fails to take into account the crossing-over of these two roles. Grammatically, the hyphen between singer and songwriter acts as a bridge, simultaneously distancing the two roles while still maintaining their relationship to one another. However, this discursive function of the hyphen simplifies a relationship that is not as clear-cut as the term proposes. In performance, musicians continue to adapt and edit their work, refining music and lyrics to meet the demands of a particular concert: adding place-specific lyrics to increase relevancy or connection with listeners; extending instrumental sections to account for a strained and tired voice at the end of tour; changing octaves and ranges for songs when unwell. These active processes of writing while singing demonstrate the possibility for blurred boundaries between roles within this genre. Placing a hyphen in the term "singer-songwriter" forces a definitive split between the two roles, a split that is 
neither as evident nor relevant when applied to the performance practices of contemporary singer-songwriters.

Ambiguities created through the use of the term "singer-songwriter" could, however, be seen as appealing to some listeners and scholars. Experiences associated with singer-songwriters are colored by difference and innovation; therefore, a term that incites some uncertainty and haziness may be preferable as it invites a conversation on variance while still acknowledging that the separation of musical acts into two distinct camps is neither useful nor valid.

MY RESEARCH IS BASED on the work of the three musicians I met at Bar Bodega in 2010, all of whom identify as singer-songwriters. They each negotiate the complex web of terminology and performance expectations in different ways, yet all eventually fall upon the classification of the singer-songwriter to best categorize their performance experiences and repertoire.

Amanda Palmer, while self-identifying as a singer-songwriter, admits that the title doesn't always fit easily. In a post on her public Facebook page in June 2014, Palmer wrote 'I love reading good, real writing about my songwriting. I think people forget sometimes that I'm a songwriter. I forget sometimes' (Palmer, 2014b). Despite this admission of occasional forgetfulness, on her self-managed Bandcamp page Palmer's $^{\text {' }}$ biography categorizes her as a singer-songwriter, as does her LinkedIn (Palmer, n.d.(a); Palmer, n.d.(b)). Hera also recognizes herself as a singer-songwriter, with the biography on her Bandcamp page reading 'Icelandic singer/songwriter based in Christchurch, New Zealand' (Hera, n.d.). Furthermore, in my interview with Hera, when asked if she identified as a singer-songwriter, she enthusiastically replied, 'Yes, definitely!' (personal communication, 2014).

On the other hand, Katie Morton identifies more as a songwriter than a singer, a distinction that has been fortified through years of being an instrumentalist. Morton's gradual journey to becoming a singer-songwriter began with writing songs for others.

I started writing pop songs. I was never going to sing. Remember I wasn't a singer. I was writing pop songs for other people to sing. That was going to be what I was going to do...but I got the bug and I kept on writing and eventually discovered artists like The Dresden Dolls, like PJ Harvey, people who were being really theatrical and expressive in ways that I hadn't felt able to be because I thought I'm

\footnotetext{
${ }^{4}$ Bandcamp is an online platform that allows musicians to independently sell their music, rather than relying on record labels. Musicians can sell physical copies of their albums, while also offering immediate downloads of mp3s. Subsequently, the website has become a widely used arena for the distribution and consumption of popular music. Read more about them at: https://bandcamp.com
} 
not a singer, I can't sing. Therefore, I shouldn't sing because I'm not what is on the box, you know? I'm not the typical so therefore I can't. I don't fit the job description. So it took me a long to time feel ok about writing for myself and that's when I think I really started to find my voice, because I wasn't writing with the intention of it becoming a pop song on the charts or anything. It was going to be just for me. But it took me a long time, even after that decision was made, to feel ok about singing in front of people (Morton, p.c, 2014).

Ultimately, however, Morton self-identifies as a singer-songwriter, while still being conscious that April Fish's music may not sound exactly like other music categorized in the genre of singer-songwriters.

This identification of singer-songwriter as performer demonstrated by all three performers illustrates how this term is often used by fans and musicians alike to describe the person making the music. The second most prevalent way this term is used is as a genre classification. Therefore, what follows is a consideration of two key means of understanding genre: as a label and as an expectational set, the latter of which I find more useful in the context of singer-songwriters.

\section{Germane Genres}

As A CATEGORIZING TOOL and epistemological framework, genres are used to declare what an art is and is not, defining it against dissimilar objects and defining it by what other units in existence are of a similar nature. Historically, genres in music have been understood in terms of stylistic conventions and a shared musical language (Van der Merwe, 1989, 3), an understanding perhaps symptomatic of considerations based on the concept of "the music itself," in which music is understood to be an object that speaks independently from interpretation. More recent conceptualizations of genre take a more holistic approach, suggesting genres cannot function outside of the cultural context they exist within. For instance, Fabian Holt identifies a genre as

[a] type of category that refers to a particular kind of music within a distinctive cultural web of production, circulation, and signification. That is to say, genre is not only "in the music," but also in the minds and bodies of particular groups of people who share certain conventions $(2007,2)$.

Holt characterizes a move away from earlier style-based understandings of genre towards an understanding that is grounded more firmly in cultural practice, emphasizing the importance of human agency and discourse in the way genre definitions are created, understood, and disseminated.

Franco Fabbri classifies a genre as 'a set of musical events... whose course is governed by a definite set of socially accepted rules,' which further sanctions the social nature of the term $(1982,52)$. Allan Moore (2001) suggests that within popular music 
studies, genres often focus on social and cultural practices and applications, as opposed to the more textual and stylistic practices emphasized in historical musicology. While I agree that cultural contexts play a crucial role in genre development, these socially-determined identifications of genre risk sidelining the aural elements of the music, privileging collective use over any musical features that are representative of a particular compendium of music. Consequently, a fine balance needs to be achieved that recognizes musical and social elements equally in the classification of genres. One way to achieve this is to conceptualize a genre as an expectational set, which highlights the role of listener engagement and fan discourse in the creation and perpetuation of genre conventions.

\section{Expectations, Predictions, and Conventions}

IN GENRE DISCOURSE, active listeners play a crucial role in developing, and subsequently naturalizing, particular expectations of sound, content, and performance practices. In light of this, I look here to cognitive musicology and consider how perceptual processes of musical expectations shape listeners' experiences of music. Musicologists in this field reveal useful insights into the listener's role in the creation and recognition of expectation in music. This research forges a link between understandings of genre that are reliant on stable texts and the music of singer-songwriters with its marked absence of texts, by drawing specific attention to the role of hearing in the development of expectations.

The unique series of conventions and nuances that become associated with a particular genre can be understood as a schema or expectational set. David Huron, a professor of cognitive and systematic musicology, writes in Sweet Anticipation: Music and the Psychology of Expectations that a schema circumscribes 'an encapsulated behavioral or perceptual model that pertains to some situation or context' (2006, 204). In Huron's own investigation of musical schemas he distinguishes a variety of expectations listeners have, created both pre- and post-listening. He identifies five elements of expectation: imagination, tension, prediction, reaction and appraisal (ITPRA). ${ }^{5}$ Huron uses his ITPRA model to isolate the distinct ways listeners shape expectations of music, identifying them as separate processes that oftentimes occur simultaneously and subconsciously, and which result in a series of expectations that culminate in a genre.

\footnotetext{
${ }^{5}$ Huron differentiates between these processes by explaining that the imagination and tension responses occur before the aural event while the prediction, reaction and appraisal responses all occur after it. For me, the prediction response sits a little uncomfortably in the post-event camp, as it relies on a series of tacit cognitive processes and assumptions made before hearing the music, that are then recognized post-hearing.
} 
Philip Tagg takes another step toward the identification of a genre's broader expectational set in his musematic analysis of ABBA's "Fernando." This mammoth 120page analysis moves towards an understanding of musical details in light of the network of cultural and personal connotations musical sounds inspire. Tagg defines a museme as a 'minimal unit of musical meaning' $(1999,15)$. He suggests that it is the combination of multiple musemes that creates an identifiable musical narrative. Tagg argues that the placement of certain musemes in juxtaposition to one another in "Fernando" represents ideological and political positions, and he sustains this argument through an examination of the song's musical structures and how these interact with paramusical contexts, which includes lyrics, images, and the song's external social climate $(1999,16)$. For example, Tagg identifies one such unit of music, which he calls the 'quena' museme that, due to its apparent South American influences, connotes

Open, outdoor spaces in a (for Northern Europeans and North Americans) far-off, exotic, ethnic rural region, probably somewhere in the high of the Andes (Peru, Bolivia, Chile). An individual (the melodic instrument) is thrown into a certain degree of relief against this environment, adding a simple, human, folksy, honest Naturvolk romantic aspect tinged with melancholy. The generous reverb adds considerably to enlarge the feeling of space and the whole 'scene' (sound 'landscape painting,' complete with ethnic individual) is faded in at the mixing console, coming into complete sonic 'focus' at bar 6 - a sort of establishing shot in sound (1999, $35)$.

This passage demonstrates Tagg's approach to analysis, dissecting small musical sections to find the body of associations each holds. Through these analyses, Tagg illustrates the social and personal nature of musical interpretation, as a museme's meaning is reliant on shared musical knowledge that draws on the interpersonal relationships between listeners and performers, and listeners and musical events. His work could be seen as intermediary between Huron's conception of textual expectational sets and the notion that these expectational sets can move beyond the text and instead be seen as arising from sociallyconstructed interpretive processes. Tagg's insistence that meaning arises from active processes of listening that draw on networks of extramusical associations, along with Huron's ITPRA model, together place the listener at the forefront of musical meaning, resulting in an approach that not only values but relies upon, listener engagement in the creation of genre expectations. This resonates with the active role listeners play in the creation of expectations of the singer-songwriter genre, particularly in the ways listener engagement on social media influence musical interpretations. I frame the following discussion of singer-songwriter expectations by building off the theories of Tagg and Huron. This reveals how the unique set of expectations for singer-songwriters grows out 
of fan discourse and the mutual existence of individual and collective interpretations of musical sounds and narrative features.

\section{The Expectational Set of the Singer-Songwriter}

BORROWING FROM HURON, I propose that particular genres also have schemas attributed to them, which influence how listeners engage with this music, and in turn, engage with the musicians and other listeners. While Huron's model of expectational sets relies on specific musical details and their respective affects (such as when one hears the dominant before a tonic), in my research I extrapolate upon this idea, conceptualizing an expectational set as one that is not only bound to textual analysis, but also augmented through listener engagement with performers. In this way, expectational sets are then able to encompass both aural content and broader performance concerns, such as narrative inspiration and on- and off-stage behavior. By understanding expectational sets as shaped by listeners' experiences, it therefore illuminates how persisting expectations of various performers have developed through engagement, which emphasizes how these conventions arise not simply within the music, but are also attributed to it.

For the singer-songwriter genre, there is an expectation among fans and listeners that the music will be intimate and confessional, and these expectations are preserved through fan discourse and biographies of particular performers (Colt, 2006; Dibben, 2009). The musicians themselves also perpetuate these expectations, with both Morton and Hera identifying in our interviews that the music of singer-songwriters should be about connection and be 'a place to share personal stories and experiences' (Hera, p.c, 2014). Ronald Lankford Jr. even goes so far as to say that 'a singer-songwriter promises an audience an intimate connection' (2010, 168). In his study of female singersongwriters, Lankford observes that in the public eye, singer-songwriters are held up as the pinnacle of truth, the catalyst for removing the boundary between autobiography and musical output. Lankford argues that the 'myth of the confessional singer-songwriter' is built on the belief that there is 'no line, and there should be no line, between a songwriter's personal life and music, and the more painful the confession, the more real the results' $(2010,8)$. This demand for pain and confession makes up the first facet of the singer-songwriter expectational set.

Further, singer-songwriter performances are usually expected to spotlight a solo performer, who is responsible for all musical output, both compositionally and in performance. While a singer-songwriter need not be a solo artist, this is typically the 
expectation listeners have (Horn et al., 2003, 198). This expectation arises from the privileging of a single person within the title itself; however the genre, despite emphasizing the role of one performer, does not eliminate the possibility for other performers, nor does the presence of another musician weaken the performance. The crucial factor is simply that the person singing is also the individual that wrote the lyrics. Regardless of musician numbers, the singer is expected to be vulnerable, singing lyrics that are as personally revealing as they are musically (Lankford Jr., 2010). In our interview, Katie Morton identified the singer-songwriter in a similar way to Lankford, saying, 'when you say singer-songwriter, I generally jump to the type of person who sits, a solo artist with a guitar or piano usually, and it will be quite lyric-driven...the word "connection" comes to mind' (p.c, 2014).

A GENRE'S EXPECTATIONAL SET is a consequence of the discursive environment in which the genre exists. These genre expectations subsequently impact what is expected of the performers of these musics, particularly in the singer-songwriter genre where there is already assumed to be a close connection between performer and song. Furthermore, these expectations of performers do not exist solely in musical performance settings, but also in everyday contexts. This schematic transfer can at times lead to misattribution, as assumptions are made about one context based on conclusions drawn from a different context. This plays out in a variety of ways, one key example being the expectation of the music to be autobiographically "honest," which can lead to the assumption that this honesty will also be present in other arenas.

The trope of the confessional singer becomes a recurring way that audiences engage with singer-songwriters, seeing them as confidants or friends, even if they have never met in person. What one expects the music to do (tell true stories) comes to bear on what one expects the performer to do (be the pioneer of these true stories in multiple contexts). Amanda Palmer fan Kristen Fiandaca illustrates this in a recent blog post, writing

I had The Dresden Dolls to keep me company...Amanda was my friend and confidant, even though I didn't actually know her personally. She put concise words to my vague thoughts time and time again with utter perfection (the girl can fucking write). Making me feel less weird and less crazy, with every song filled with honesty and confession (2014).

The blogger demonstrates how the expectational set of the singer-songwriter genre has come to shape listeners' expectations of performers and, more importantly, has come to mediate the ways listeners engage with this music. 
Expectations of the genre are subsequently used as a means by which to understand what is happening in the lives of these performers, with listeners transferring the tools available for deciphering a musical repertoire onto how they engage with that performer's daily activities, social media interactions, and off-stage behaviours. This schematic transfer represents a transition from musical interpretive strategies to engagement in everyday contexts. This shift is all the more relevant in a discussion of singer-songwriters, due to the privileging of the personal in this genre. The respective expectational sets of the genre and the person are not clean-cut; expectations elide the two realms, due in part to the close relationship between the person and the genre (as outlined in the genre label itself), but also thanks to the ambiguities inherent in this field of music-making.

\section{Expectational Sets as Indicative of Listener V alues}

THE ABOVE DISCUSSION of the expectational set of singer-songwriters reveals the key role listener engagement plays in the perpetuation of significant conventions - musical and otherwise - associated with certain repertoires of music. It draws attention to questions of value, with listeners' expectations spoken about and mediated through conversations rife with value-based judgments. Theories of how and why we place value on certain performers are paramount to the perceived intimacy of the singer-songwriter genre and performative act, demonstrated through this music often being referred to as the musical equivalent of a personal diary (Hera, p.c, 2014; Lankford Jr., 2010).

In his book Performing Rites Simon Frith explores a variety of topics that spark conversation and debate amongst popular music listeners. Frith splits his discussion into three sections, thinking about the "talk" surrounding music, the music "itself" and then the significance of this music. Running through all three sections, though, is the refrain that talk and emotions matter. Frith sustains an argument throughout that, instead of ignoring what is being talked about in casual, everyday conversations, these topics should carry over into academic analyses of music.

Consideration of the prevalence of value and how this elusive quality is assigned to various genres, artists, albums, and songs is one of the key themes throughout Performing Rites. Frith writes, 'part of the pleasure of popular culture is talking about it; part of its meaning is this talk, talk which is run through with value judgments' (1998, 4). At its most basic level, a statement of whether we like or dislike something tells us more about the speaker than it does about the thing being spoken of. As listeners, we consciously and 
unconsciously weave value judgments through our talk about the music we engage with. In particular, these judgments often underpin listeners' discussions of the commonly asserted values of how honest or truthful an artist is. Paying attention first to the value judgments that are written between the lines of our musical interactions, and then subsequently to what these reveal about the speaker and also the music, uncovers a range of expectations that govern our engagement with a particular genre and individual artists, which culminates in an expectational set.

ONE RECURRENT AND UNAVOIDABLE value judgment that arises both within the classroom and beyond is "authenticity." A deceptively simple term, authenticity is fraught with contention and a plethora of meanings, all signified by this single word. Given the difficulty surrounding this term, it is one I bring up with caution. However, in addition to its tendency to appear and re-appear in fan discourse surrounding singer-songwriters, its presence within music studies makes it impossible to ignore.

As a measure of worth, authenticity is present in many fields and contexts, and this goes some way to explain its power. Authenticity has become a marker of "good" products or experiences and as such has become a term acknowledged and utilized by people in academic and vernacular discussions alike. It can be seen everywhere - on travel websites, food packages, restaurant signs, clothing brands. In an everyday context, authenticity stands for a genuine and "real" product and experience, setting itself up in opposition to counterfeit products or "fakeness". In an examination of how to deliver authentic products, James Gilmore and B. Joseph Pine II in their book Authenticity: What Consumers Really $W$ ant identify five markers of authenticity in circulation: natural authenticity, original authenticity, exceptional authenticity, referential authenticity, and influential authenticity (2007, 49). While all five of these criteria could be applied to the music of singer-songwriters, the two that appear most frequently in fan discourse are the natural and referential authenticities.

Natural authenticity, as defined by Gilmore and Pine, is a state of immediacy, and in music this is demonstrated through raw presentations of skill - performing in an unmediated and unedited fashion that leaves nothing to spare. This category mirrors the way authenticity often appears in musical discussions, where it is associated with the voice and specific ideologies suggested by various vocalities. It is frequently used interchangeably with words such as "honest", "real", "genuine," and "truthful," and unedited voices are frequently interpreted as being more authentic. The voice as a 
signifier for this authenticity will be dealt with in my final chapter, where Palmer, Hera, and Morton's vocalities are examined in relation to "authentic" sounds.

Gilmore and Pine's second category of referential authenticity is evoked when a product refers to some other context, 'drawing inspiration from human history, and tapping into our shared memories and longings' (2007, 50). Singer-songwriters who appear to refer to their own lives in their music increase their value and perceived authenticity in the ears of listeners, due to perceptions of honesty. As noted by Richard Middleton, this authenticity is increased through asserting "real" emotions and stories that refer to the performer's truth and reality $(2006,231)$. By explicitly and implicitly drawing inspiration from their own history - a history that a fan would recognize and understand - the performer can strengthen the referential authenticity attributed to them and their music.

Within a musical context, notions of authenticity play a key role in the development and perception of various musical practices. Peter Kivy's seminal 1995 study Authenticities: Philosophical Reflections on Musical Performance remains one of the most notable texts on the subject, aimed at demystifying authenticity's presence in European art music by considering how it is assigned to various repertoire and performance practices. Kivy classifies authenticity into four distinct categories: authenticity as intention, authenticity as sound, authenticity as practice, and the "other authenticity." He claims that the first three are commonly acknowledged within discussions of historical performance practice and the fourth, while not often talked about, in fact underpins and informs the other three types. The "other authenticity" is defined as being 'authentically one's own, emanating from one's own person' (Kivy, 1995, 108), and connotes perceptions (and values) of truthfulness and honesty in performance. Performative honesty is achieved more through reception than production, but it relies heavily on interpretations of truthful and "real" production techniques, where performers are valued for using their music as a means of individualized self-expression.

Kivy's use of the word "other" for the fourth type of authenticity could be seen at the outset to marginalize it, calling attention to its separated position within musicology and by doing so emphasizing and contributing to its marginality. However, he uses this space of the "other authenticity" to show how it applies back to the three more commonly agreed-upon forms of historical authenticity (intention, sound, and practice), showing its prevalence in existing conversations. Although this "other authenticity" is commonly left out (by name if not by nature) in discussions of European art music 
traditions, in popular music this is the main type of authenticity inferred, whereas the other three are more marginalized. That is to say, in popular music contexts, particularly that of the singer-songwriter, value is assigned largely on performing in an authentically personal and "real" style - a style that is expected to reflect the personal nature and story of the performer.

In scholarly discourse on popular music, notions of authenticity are central to fan engagement, academic critique, and journalistic criticism. In his 2002 article 'Authenticity as Authentication' Allan Moore explores the way in which the rhetoric of authenticity occurs within a popular music context, identifying a multiplicity of situations in which the word is used as a validating terminology: authenticity as opposed to fakeness, authenticity as opposed to modernity, authenticity as opposed to commercialism. In relation to singer-songwriters, Moore specifically notes that this term is frequently used to describe these performers and their repertoire, 'where attributes of intimacy... and immediacy...tend to connote authenticity' $(2002,211)$. His identification of the multifaceted treatment of authenticity in discourse results in the word signifying a collection of different value judgments, all bound up in a single word. This conflict of meaning results in much confusion and anxiety about the word's use and dominating presence in discussions. Moore argues that some of the confusion surrounding the term could be alleviated by considering all applications of the word as contributing to one of three broad conceptions, or "poles", of authenticity, one of which seems especially relevant for a discussion of singer-songwriters. Moore's first pole, known as “first person authenticity", is the one I see as most closely aligned with singer-songwriters, although Moore himself does not talk about it in reference to this genre. Otherwise referred to as "authenticity as expression," it is this value marker that is often woven into conversations about singer-songwriters by listeners, fans and critics, such as the credibility assigned to Amanda Palmer upon being judged as emotionally and honestly authentic (Powell, 2012). Speaking of this brand of authenticity, Moore writes that its presence in popular music is undeniable and that it 'arises when an originator (composer, performer) succeeds in conveying the impression that his/her utterance is one of integrity, that it represents an attempt to communicate in an unmediated form with an audience' $(2002,214)$.

A further exploration of the sometimes problematic ways notions of authenticity appear in popular music discourse is Hugh Barker and Yuval Taylor's 2007 project Faking It: The Quest for Authenticity in Popular Music. The authors cover ten radically different musical contexts, ranging from disco to punk to electronica, examining how authenticity 
is sought by performers, bestowed upon them by listeners and critics, and utilized as a tool to sort the "good" from the "bad". Like Moore, Barker and Taylor propose that authenticity is a better measure for what is valued by the person determining the level of authenticity in a performance, rather than what is necessarily inherent in a performer or performance. Of particular significance to my work here is Barker and Taylor's consideration of the development of autobiographical song. Autobiographical songs are identified as 'songs that are truly about the singer (or writer) more than about anything else, that tell the truth, and that refrain from bleaching out facts through generalization' (Barker \& Taylor, 2007, 104). Furthermore, Barker and Taylor explain that these songs have become a 'talisman of [performers'] personal authenticity... in order to boast of how "real" they are' $(2007,105)$. Asides from the authors' distinction between singer and writer, which in the case of the singer-songwriter is a distinction not worth adhering to, the definition of autobiographical songs provided in this text aligns closely to the expectations of the singer-songwriter's repertoire. Interestingly, however, Barker and Taylor choose not to discuss autobiographical songs in relation to singer-songwriters, despite the intuitive connections that could be made, preferring to instead follow the transformation and revitalization of blues songs through the years. Perhaps the decision to feature singer-songwriters in a subsequent chapter on the contention between the marketplace's dual priorities of big bands and solo artists is reflective of the apparent belief that the connection between singer and narrator is too obvious within the music of singer-songwriters to warrant proper discussion. If these singers are viewed as being synonymous with the narrators in their music, a discussion of this genre in regards to autobiographical songs would then be superfluous. This misleading assumption taints Barker and Taylor's succeeding discussions of singer-songwriters, which suggests that it could have been a motivating factor behind their decision to feature a different repertoire alongside autobiographical songs. As I demonstrate in this thesis, however, the relationship between singer-songwriters and narrators is highly complex and focused discussions on this affiliation is not only warranted, but also enlightening.

In my own work, I hesitate to put forth a single definition of authenticity, deferring instead to the number of meanings fans and listeners imbue it with. My approach to authenticity is dictated by the conversations it is already present within, specifically those related to perceptions of "realness" and presentations of self, drawing on this thesis' focus on music as a tool for expression of perceived autobiographical truths. 


\section{Community and/ as Interpretation}

A FURTHER KEY VALUE of popular music, which has been hinted at throughout this thesis thus far, is the importance of community and collective engagement. The conventions associated with the singer-songwriter expectational set develop through individual and communal listening habits and the subsequent discussions these listeners have together. In this way, one can consider expectational sets as the product of the overlapping interpretive horizons held by listeners. It highlights how musical expectations grow out of discourse, rather than simply existing as stylistic expectancies built into the genre, and contributing to this discussion is Stanley Fish, whose notion of interpretive communities identifies the individual, yet collective, nature of musical meaning.

In Is There a Text in This Class? The Authority of Interpretive Communities Stanley Fish examines how interpretation is created in the minds of readers, based on personal and communal involvement with texts. Fish proposes that understandings of meaning should move away from metaphors of searching towards those of creation, emphasizing the active role readers take in forming meaning, rather than simply finding it. This approach highlights how reader subjectivity leads to the creation of meaning and the "finding" of perceived authorial intention and is relevant not only to literature but also to music. Performers may influence the path listener interpretations take by emphasizing certain details about a song or event; however, ultimately understandings of meaning are contingent on the wealth of knowledge and expectations held by listeners.

Most pertinent to a discussion of singer-songwriters and fan interpretations is Fish's concept of the "interpretive community." The term describes a group of people with shared interpretive tendencies, thanks to mutual historical, social, and cultural experiences and belief systems. These strategies are subsequently employed when engaging with a text and vary depending on the context in which they are being used. Fish writes that

An interpretive community is not objective because as a bundle of interests, of particular purposes and goals, its perspective is interested rather than neutral; but by the very same reasoning, the meanings and texts produced by an interpretive community are not subjective because they do not proceed from an isolated individual but from a public and conventional point of view $(1980,14)$.

The ideological framework presented by Fish on interpretive communities is useful when theorizing the ways different listeners engage with the music of singer-songwriters. It is possible to see how fanbases, which frequently use information to create meaning that casual listeners may not know or recognize, can be theorized as interpretive communities. 
Conceptualizing fandoms as interpretive communities that have joint access to information that they draw on collectively (consciously or subconsciously) when listening, begins to explain the multiplicity of meanings attributed to music and highlights a key process in the way genre expectations are formed.

In his ethnographic study on fans of singer-songwriter Bruce Springsteen, Daniel Cavicchi also suggests that community plays a crucial role in the shaping of listener's interpretive strategies - echoing Fish's perception of the function of interpretive communities. In Tramps Like Us: Music and Meaning Among Springsteen Fans, Cavicchi's research model is driven by listener experience and he identifies five key ways fans contextualize the music they hear and subsequently discover (or perhaps construct) meaning in it. The five methods suggested, drawing on a complex array of information, are: summary associations, aesthetic associations, political associations, biographical associations and personal associations. Cavicchi examines perceptions of the meta-performer, considering how the way Springsteen is understood in one arena impacts how he is understood in another. This reflects one of the significant facets of the singer-songwriter expectational set, where performers are perceived by listeners as honest, due to that listener's interpretation of the performer's music as honest. The concept of the meta-performer suggests that a performance should be understood broadly, encompassing clothing, venue, before- and after-show behavior, as well as any related activities undertaken on social media platforms. This expansive definition is one that has influenced where I have chosen to visualize the frame of performance in my research, inclined to include, rather than omit, various extra-musical elements in my conceptualization of the performance space, due to the schematic transfer that often occurs where fans use information they have gathered in a variety of contexts to understand "the music itself".

I return to Cavicchi in my second chapter where I address matters of interpretation through the lens of first person narratives. Until then, I move to a discussion of banter, a performative technique that is frequently used by listeners to interpret a performance and performer, and is identified by Cavicchi as playing a vital role in the understanding of music. As an important facet of the singer-songwriter's expectational set, I approach banter as interpreted by fans through a lens of informed understanding and practices forged from collective knowledge. 


\section{III: Sound-Checking the Theory}

\section{Banter, Patter, and the Power of Speech}

IN PERFORMANCES BY singer-songwriters, banter is a common element of the performance structure. The term banter is one that is used by fans of the singer-songwriter genre and, in particular, fans of Amanda Palmer, to describe the spoken interludes that are woven through and around musical performances. Due to the term already being in circulation, I have chosen to continue the trend and use it here. Performers talking before, after, and between songs offer listeners insights into particular compositions and thematic content within lyrics. It may also engender a sense of community among concert-goers and performers, an effect that musicians achieve through using banter as a means of appearing personable, friendly, and connected to the local concert context. As a salient part of the singer-songwriter genre and one that reveals, or at least appears to reveal, information about the "true" performer, banter is symptomatic of the crossing over of expectational sets from musical to performer expectations.

These conversational interludes can take the form of introductions at the start of a night, often utilized to involve the audience in the performance, including phrases such as 'How are you tonight, Wellington?' or 'Who's ready to have some fun?' Performance banter appears in other forms, also, such as spoken transitions between compositions offering insights into particular songs. Banter acts on at least two levels: pragmatically, it can provide signposts throughout concerts, indicating what has just occurred and what is to come; on a personal level, it also engages with audiences and humanizes performers. Musicians take different approaches to incorporating this element into their performances. Some focus on the introduction of particular songs, sustaining conversations on the present event, keeping the audience's attention on the here and now and engendering a sense of "living in the moment"; others use it as an opportunity to personalize the concert by incorporating information about past or future events and providing details about their life. Both of these strategies can ultimately influence audience's subsequent interpretations of various songs.

\footnotetext{
${ }^{6}$ Here Wellington is used as a specific example, but one that does not exist in isolation. Including the place name of a city, country, or venue, is a performance trope that evokes a sense of community. This technique invites the audience into the performer's actions, personalizing the event and increasing its relevancy for a particular audience. Meant to achieve a positive reaction, it can also backfire when performers call out the wrong place name. In a 2013 performance in Wellington, Cliff Richards called out 'Good evening Auckland' stunning audience members and defeating the initial purpose of the act. Rather than asserting the unique nature of Richards' relationship to that particular audience, he instead marginalized them, disrupting interpretations of personalization.
} 
The presence of banter is certainly not unique to the music of singer-songwriters. In his account of country music in Texas, Aaron Fox reports of the pervasiveness of "stage patter," which blurs boundaries between what is performance and what is not. Fox observes that stage patter is used before, throughout, and after songs, often with the effects of creating a sense of coherency, emphasizing locality and highlighting the specificity and unique nature of a individual performance, frequently referencing the exact town or bar they are in, or what the day's weather has been like $(2004,245)$. He writes that

"Spoken" discourse also shapes the boundaries around song performances. Stage patter, bandstand talk, and interactions with audience members (using intonationally and dynamically heightened speech) can also be used to move between the spoken frame of song performance and full singing (Fox, 2004, 275).

The idea here is that moments of speech or speech-song are used to connect fully sung sections, and this shifting nature of the performance frame ultimately leads to there being no distinction where a performance starts or ends. Fox also identifies a further affect of stage patter is that, either explicitly or implicitly, it extrapolates on the idea of the personalized "self" of the performer. The persistent presentation of self through both speech and song leads to a personalization of and connection with a performer.

However, despite stage banter (or "patter") being incorporated into performances of music from a variety of genres, it seems to hold a special place within the singersongwriter genre. Audio recordings of live singer-songwriter performances emphasize the importance of banter by including all the spoken intermissions on the released CDs. An example of this is on Hera's 2008 album Hera Live at Al's, where each track either begins or ends with the musician talking. In the final thirty seconds of the track "Ofie," Hera introduces the next song on the album "Hafið Dennan Dag," explaining conversationally 'I'll tell you about this song...this is a song in Icelandic and it's, when I was little, I wanted to grow up and be a mermaid. And because I couldn't, I wrote a song about it' (Hera, 2008).

On another track, Hera jovially chats as she pours herself another cup of tea, and exclaims over seeing a spider, at which point she stops her set to save it. These spoken fragments - with some holding more significance for those who were in attendance at the live performance by their explicit referencing of specific occurrences at that particular show - continue the projection of the personalized self, as described by Fox, and further indicate the importance of banter in the singer-songwriter framework. While those who attended the original concert may make more sense of the banter captured on record, the stories and snippets of conversations included on the CDs still play a vital role in framing 
performances and shaping the meaning drawn from the music by listeners not in attendance at the live performance.

Amanda Palmer also frequently utilizes banter in her shows, sharing tour and travel stories that are woven into stories about the conception of certain songs and memorable performances. This is particularly evident at Palmer's "ninja gigs." This term refers to the impromptu free concerts Palmer holds in public spaces worldwide. Advertized through social media, Palmer asks for suggestions of public spaces in cities she is visiting and holds pop-up concerts there, which are often accompanied by a picnic or group sing-a-long. In 2013, she held her first Ninja Parade, which took place in Wellington, New Zealand and had attendees touring around the city, playing ukuleles and visiting various local attractions to perform and take photos. The Wellington Ninja Parade accurately demonstrates one way that banter is interwoven through regular conversations and musical performances, which creates a sense of inclusivity amongst those in attendance and heightens Palmer's "relatability," augmenting the "she's just like us" mentality held by many of her fans.

\section{Performance Parades and the Parading of the Performer}

TO EMPHASIZE THE SHIFTING BOUNDARIES between "performance" and "everyday," what follows is a moment of ethnographic reflection. It depicts the afore-mentioned Amanda Palmer Wellington Ninja Parade from 2013 and through a focus on banter, reveals how singer-songwriter performance is, or is at least portrayed as, arising from and working in conjunction with, the performer's own life and experiences. Once again, ethnographic writing is used here to stress the role of listener and fan experience in the development of processes of engagement, while also illustrating a particularly pithy example of how banter can function in live performance.

ON A CLOUDY SATURDAY on September $2^{\text {nd }}, 2013$, twenty people gather around a brightly painted piano on Wellington's waterfront. The group is comprised of a mixture of ages, genders, and ethnicities, and people mill around, talking amongst themselves. More than a few take turns to play on the poorly-tuned-but-functioning piano. I arrive alone, and anxiously clutch my cellphone, desperate to minimize my feeling of isolation in the crowd. Before long, however, Katie arrives and we get chatting about what April Fish has been up to lately. Katie hands me a download card for their new album Blurred, which I pocket, promising to give it a listen upon the conclusion of the day's events. A girl 
nervously approaches us and introduces herself to me as Shauna, a fellow Amanda Palmer fan who I had been talking with on Twitter earlier in the day. As the three of us talk, our conversation is interrupted by the arrival of Amanda, who with great ebullience approaches the piano and plays a few dramatic alternating D minor and Bb Major chords before turning to the crowd and warmly greeting us.

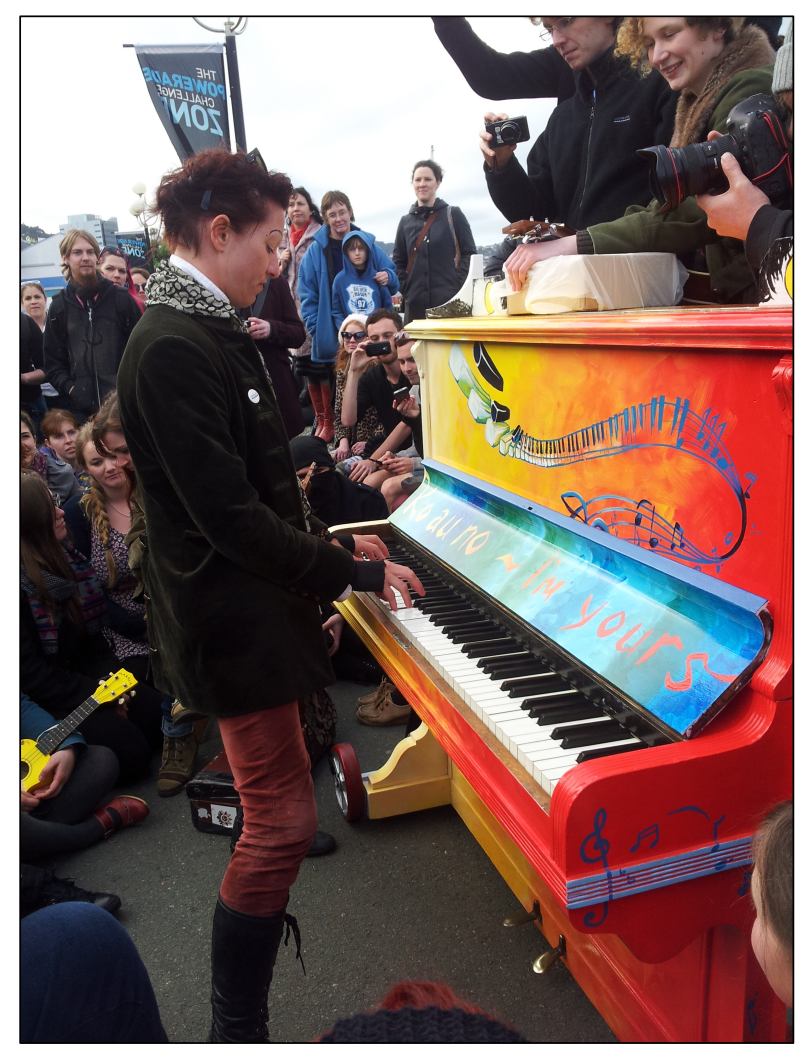

Figure 1: Amanda Palmer, Wellington Ninja Parade Photo credit: Ailsa Lipscombe (2013)

Amanda returns to the piano and kicks off with "Half Jack." This portion of the concert at the waterfront is woven together by performances of primarily older works off her solo albums and constant chatter between Amanda and the concert-goers, with a side serving of panic when Amanda plays the keys a little too hard and manages to break the piano. Once fixed, Amanda steps dramatically away from the piano, picking up her ukulele and declaring there's time for one more song, and a new one at that. While tuning her ukulele, she tells us the story of how she learned this song off a lonely, coffeedrinking purple-haired girl in a small café in Boston. We learn the song line by line, with Amanda feeding lyrics to us until everyone is singing the refrain 'she spends her money on cigarettes and such' loudly and with great vigor. As Amanda sings, the crowd cheers, and more people gather around the piano. Some have been reeled in by the spectacle 
itself, intrigued by the noise and music, and others have seen the various social media announcements about the event. By the time we leave for the next destination, over fifty people are surrounding the piano, sporting drums, ribbons, banners, and cameras.

We move off, crossing the bridge into Civic Square and parading into the Wellington City Library, where the young adult section has been cleared to create a makeshift stage. Already behind schedule and determined to make it to the final stop before dark, we only stay in the library for two songs - a cover of Radiohead's "Creep" and a repeat performance of the cigarette song, which is our nominated "Parade Anthem" before moving onto the Museum of New Zealand Te Papa Tongarewa.

The parade continues for six hours, while the crowd fluidly dissipates and grows. Eventually, we make it to Garrett Street Collective. Sitting at the piano, Amanda starts to improvise, creating a musical accompaniment for the stories she begins to tell. I am standing in the front row with Shauna, Katie having left to attend a band practice. The wooden floorboards reverberate with the footsteps of still-arriving fans, some of whom had attended the parade but many of whom have come purely for this final, more "formal" concert. Amanda thanks us for today and shares her favourite moments, lamenting over the first broken piano - an ironic prelude given that she is to break this piano in the same way later this evening.

The circling, trapped motif of "Trout Heart Replica" begins to play. The melody bounces around the room, hypnotically drawing listeners in. And as it plays, Amanda talks. She tells us about how her relationship status was complicated when she first started seeing Neil Gaiman. She regales us with stories from a previous tour, which end with her arriving at Neil's house. Amanda takes us on the journey with her as they decide what to eat for dinner, and Neil excitedly announces that he has an "awesome and foolproof" method of cooking trout. It's decided that they'll go to a local trout farm, collect the fish, and come home to cook. Amanda, a vegetarian who occasionally eats fish "if the situation demands," speaks of her moral dilemma upon arriving at the farm, disgusted at the thought of the fish being killed but "spiritually obliged" to witness it. Going into the back room with her friend, they watch the fish being placed on the wooden board and killed, their tiny hearts cut out of their fleshy bodies. Here, Amanda laughs, before asking 'did you know that a trout heart can beat outside of its body for over a minute?!' She tells us how the trout's heart continued beating as it lay in the butcher's palm, and how the longer she looked at it, the more she felt that that trout's heart was her heart, beating even though it had been ripped from her body during her relationship breakup. 'That's MY 
heart!' she cries, the words raw and full of despair. The whole time she talks, she continues playing the haunting, circling melody of the song, linking her story and personal experiences closely to the song itself.

Amanda's voice trails off, her words drowned out by the insistent piano motif that continues to play for a full minute before Amanda's voice re-enters, this time singing the first line of the song. It's hard to forget the heart-wrenching emotion that filled Amanda's words and voice just moments before, and as she crescendos through the song, I visualize the poor trout's gory fate; but even more so, I imagine Amanda's heartbreak, the sad symmetry between the trout and the performer saturating my experience of the song being sung.

THE FREQUENT ALTERNATION between spoken and sung moments as demonstrated in Palmer's performance in this ethnographic reflection contributes to a sense of the music being a place for the expression of personal truths. Boundaries between the performance frame and everyday life become further blurred once one takes into consideration engagement on social media networks, where the information imparted in one arena (virtual, on "stage", in "real" life) becomes used as a means of understanding and interpreting information and events in another arena. The way listeners interpret the information they receive in these multiple arenas is an important facet of the singersongwriter genre and plays a vital role in how listeners negotiate the performer's "page to stage" relationship, where details written into lyrics are subsequently shared and performed. Music scholarship has not always captured this negotiation well, but there have been a number of literary theorists who have begun to unravel this complicated relationship between author and text. While I do not think this theoretical transposition from narratology to musicology is perfect, it proves a useful place to start. In the following chapter I question differing interpretations of the author(s) in music and examine their roles in musical texts and performance. In particular, I consider how literary theories of authorial presence both succeed and also fall short in clarifying the author's place in texts and in performance. I argue that the addition of the performer makes the current methodologies surrounding authorial presence unsatisfactory and unsuitable. Instead, a new approach that takes these interdisciplinary models into account and also acknowledges the role of the performer (and listener) is a more useful way to understand the complex relationship between author and narrator, and narrator and narratee. 


\section{Chapter Two \\ What's in an "I": Locating the Story of the Singer-Songwriter}

\section{I: The Search for the Author}

THE INTRICACY OF AUTHORIAL PRESENCE in live musical performance warrants borrowing from literary studies in interpretation and authorship to help elucidate the multiple complex processes at play in the author's development from "text" to stage. In literature and music alike, the author's presence is brought into question when the author explicitly implicates themselves within their work. In the context of my research, I define the author as the person responsible for the act of composition and lyric writing; the person whose music and words are actualized through performance. This search for an author is led by attempts by fans and listeners to "find" the author within lyrics and also within musical and stylistic decisions in performance. While it would be erroneous to suggest that in all (or, in fact, any) musical cases the author is synonymous with the performer, there are certain genres where this binding of the two figures is more justified than others. In the world of the singer-songwriter, where the genre title explicitly states the connection between the two spheres of activity (singing and writing), there is an overt conflation of distinct creative roles, emphasizing the presence of a single "author" in both the music and performance. This conflation leads to an elision of interpretive practices that results in the expectations of the performer impacting the expectations of the author, while also significantly altering understandings of musical narratives.

When Amanda Palmer stood before us at the Garret Street Collective and shared her story of fish hearts and broken relationships, she tied her personal self to the music she writes and performs. To a certain extent all performers are implicated in their music and perceived as such by listeners based on their understanding of the musicians' compositional practices and/or performative acts. However the explicit linking of autobiography to lyrical content seen in the singer-songwriter genre, as demonstrated by Amanda Palmer in her introduction to "Trout Heart Replica," might be taken as a direct invitation to associate performer with song, author with story.

Authorial presence is an important component of performance to mention, in large part because listeners and fans are already discussing it. Questions of authorship dictate fan discourse, online and at concerts, and the "discovery" of the artist's voice in their work (both in lyrics and in music) is often considered the peak of musical 
engagement. While I am sure that these informal conversations are not directed by a conscious application of literary frameworks, the similarities between the interpretive processes utilized by listeners and the theoretical narrative approaches of this thesis are strong. The transformation of my interpretation of "Trout Heart Replica" upon hearing Palmer's emotional narrative at the concert demonstrates the importance of authorial presence to listener experience, particularly in how others in attendance at the show echoed these shifts in interpretation.

\section{Real Authors, Implied Authors, and Authorial Equations}

TO OPEN THIS DISCUSSION on interpretations of authorship in music, I look first to Karol Berger who acknowledges the multiplicity of voices associated with individual art works. In $A$ Theory of $A r t$, Berger writes

In written literature and music, as well as in painting, the author is, obviously, the creator of the immediately speaking "voices" he employs to present the world of his work, but, less obviously, he himself does not belong to this world...note that this is the case even in the most scrupulously honest autobiography or autoportrait: the real world of the real author is not the same as the world of the personage the narrator presents in his story $(2000,184-185)$.

Berger's quote demonstrates the challenge of dealing with performers, as he conflates literature, music, and visual art, suggesting that the problems each face are analogous. While I agree with his point of the author's complex place within art - as the creator of the speaking voices but not necessarily represented by these voices - what he misses is the role of the performer in music. How to designate responsibility and ownership to these various voices in a musical context is difficult and occupies much of the conversation between fans of singer-songwriters, both online and in person, and is further complicated by the presence of the author/composer in the act of performance an element which is not examined or even acknowledged by Berger.

A more realistic, yet more complicated, way to think about the negotiation of these voices is to examine Wayne C Booth and his notion of implied authorship. In The Rhetoric of Fiction, Booth suggests that the Real Author/Implied Author dichotomy ${ }^{7}$ illustrates how an author presents a version of himself or herself on the page. This version embodies a persona of the author by representing a part of the author's whole. When engaging with an author or person, it is their implied author that one has access to, as each interaction one has - on the page or in person - is mediated through personae

\footnotetext{
${ }^{7}$ Narrative theorists, such as Wolfgang Iser, have further extended the Real Author/Implied Author binary. The expanded schema consists of Real Author - Implied Author - Narrator - Narratee - Implied Reader - Actual Reader and emphasizes the multiple personae of characters and readers, while continuing to acknowledge the persona(e) of the author.
} 
that belong to the individuals involved. As such, it is the sum of a person's multiple implied authors that, in their cumulative form, represent the author proper. In literature, Booth notes that this implied author, rather than always being presented through the speaker, instead underpins the text as a whole. Writing on this, Booth explains,

It is a curious fact that we have no terms either for this created "second self" or for our relationship with him. None of our terms for various aspects of the narrator is quite accurate. "Persona," "mask," and "narrator" are sometimes used, but they more commonly refer to the speaker in the work who is after all only one of the elements created by the implied author and who may be separated from him by large ironies. "Narrator" is usually taken to mean the "I" of the work, but the "I" is seldom if ever identical with the implied image of the artist $(1983,73)$.

Booth's description of the Implied Author is interesting for many reasons, but particularly for its similarity to how Amanda Palmer describes the way she conducts her personal life alongside her career. Palmer, speaking at Green Mountain College in 2012, explained that 'I am Amanda Palmer both in my personal and professional environments, but there are different versions of myself (as cited in Miller-White, 2012). Booth's identification of the Implied Author as a 'second self reflects Palmer's depiction of her 'versions of self', and they emphasize how these other selves exist both within the body of the person and as a separate, crafted entity.

Notions of implied authorship still perhaps sell short the active role readers, and in my case listeners, play in the construction of meaning. In his assessment of meaning, Jonathan Culler argues for the agency of readers, identifying meaning as both inherent within a work and as a creation through reader engagement. Culler highlights a recurrent challenge in literary criticism, namely that meaning is problematic precisely because it lacks an agreed-upon meaning. While some consider meaning to be embodied within a word and sentence, others believe meaning is that which is intended by the author; still others claim that meaning is in the context of the utterance, and more still believe meaning is created purely by the listener's (or reader's) reception of that utterance (Culler, 2000, 65). As scholars, we are left with one word (meaning) that stands for four methods of interpretation based on intention, text, context, and readers. This multiplicity of methods for understanding (or creating) meaning stands true in music, also. Therefore, a listener's desire to understand the "true" meaning of a particular song or artist is fraught from the beginning. Despite any inherent meanings there may be within the music or text, the only access listeners have to these is through interpretation, which is a decidedly subjective task.

This assertion that meaning is both within a text and outside of it is expressed by Roland Barthes, who late in his career, lamented the dominance of auteurist criticism, 
where understanding a work rests on understanding the author's place and vision within it. ${ }^{8} \mathrm{He}$ argues that 'the explanation of a work is always sought in the man or woman who produced it, as if it were always in the end, through the more or less transparent allegory of the fiction, the voice of a single person, the author "confiding" in us' (Barthes, 1977, 143). In many forms of popular music, collaboration and teamwork are prominent and in these cases it can be understood why a theory of interpretation based on the 'voice of a single person' would be misguided. However, the singer-songwriter's craft insists that the one artist is both writing and singing the music; thus it is not hard to see how interpretive practices, such as the ones Barthes is speaking against, have come to play such an important role in the reception of this music.

Barthes notes that despite meanings manifesting as seemingly universal things, an interpretation at heart is a personal understanding based on a network of associations and information available to individual readers. Depending on a reader's background knowledge, their wealth of experiences, and their involvement with a text and author, their understanding of a particular work will be at times remarkably different from another reader's, and at other times similar. Barthes writes that 'we know now that a text is not a line of words releasing a single "theological" meaning (the "message" of the Author-God) but a multi-dimensional space in which a variety of writings, none of them original, blend and clash' $(1977,146)$. Stanley Fish's theory of interpretive communities acts here also as a strategy for negotiating the perceived contradictions between authorand reader-based understandings of interpretive authority. It offers a way of reconciling the existence of meanings both immanent within a text and the endless subjective understandings readers have.

Simon Frith's suggestion of the way voices work in popular music - in performance and in composition - brings these literary theories into an explicitly musical context. Frith proposes that in popular music, there are many "voices" working cryptically and in conjunction with one another, even in a song performed by a solo musician (1998, 183). First and foremost, there is the voice we hear singing the lyrics. Secondly, there is the voice of the author/composer, which is responsible for the composition of lyrics and music but is not necessarily represented by the voice speaking the words. Furthermore, there is the voice of the narrator, at times conflated with the other voices present but

\footnotetext{
${ }^{8}$ Wimsatt and Beardsley echo this attitude. Their development of the Intentional Fallacy states that judging a work based on the author's intention is a misguided approach to literary criticism. They argue that texts should be analyzed as dramatic works and attributed to the dramatic speaker of the narrative, rather than an all-seeing author figure.
} 
fundamentally existing as a separate entity. By highlighting the many ways we can understand voice in music, Frith emphasizes the agency of listeners, revealing how their experiences play a crucial role in the interpretation of the varied voices present.

To some this consideration of voice(s) in music may recall Edward Cone's 1974 study, The Composer's Voice. In this work, Cone suggests that the author figure (otherwise referred to as the composer) is a reoccurring trope in musicological discussions that arises in relation to considerations of intention and the realization of the author/composer's "true" meaning of a text through performance. Cone proposes a new communication archetype to support listeners' desire to understand the complicated, convoluted, and compelling relationships between singer and song, author and performer, narrator and narratee. He sets forth the following equation: vocal persona + virtual persona $=$ implicit persona as a way of better understanding these relationships. The equation applies to a piece of music in the following way: the vocal persona is represented fully by the human voice and the music's melodic line; the virtual persona is an imaginary construct represented by the instrumental lines; and the implicit persona is the sum of both personae (Cone, 1974, 911). Cone writes of the implicit persona that

Although its medium is a compound arising from a mixture of the vocal and the instrumental, it is held together by the unifying power of the musical line. As the vehicle of the composer's complete message, it can also be called the composer's persona. Note, however, that this means not "the persona of the composer" but " $a$ persona of the composer"; for the persona of each composition is uniquely created by and for that composition $(1974,18)$.

This trichotomy of the vocal/virtual/implicit personae, when mapped onto the singersongwriter genre, falls short. The equation proposed by Cone focuses on one step of the performance communication model - highlighting compositional practices but neglecting to account for performance and reception. While Cone's theory prioritizes one step, and in doing so suggests the clear separation of each step of the model, recent work in performance studies by Nicholas Cook argues that the reality of musical communication is much more flexible than these three distinct categories suggest, in part due to the multiple sub-stages that exist, such as the printing of sheet music, or the distribution of audio recordings (Cook, 2001). Cone's equation relies somewhat on acts of interpretation, therefore inferring a sort of listener, whether they are an actual or idealized listener, but his model itself prioritizes the act of composition over any other process. The bulk of Cone's repertoire is attributed to deceased composers, significantly reducing the chance of having the composer also act as a performer. This removes the immediate need for his model to consider the role of performers in the search for the author. What makes this 
triad of vocal, virtual, and implicit personae more complicated in the genre of the singersongwriter is that the music is almost exclusively performed by the composer, exemplified in the musicians and music featured throughout this thesis. In this genre, boundaries between composer and performer are flexible and the ability to clearly mark what activities are the composer's responsibilities and which are the performer's is a luxury not afforded to this music.

This certainly does not make Cone's theory redundant for a discussion of singersongwriters; instead it makes it a fascinating model to apply to this new context, grappling with the various ways it fits comfortably or sits uneasily in these conversations. According to Cone's theory, the implicit persona lives within the text and can be understood through textual analysis, or presumably through observation of performances. For the singersongwriter however, the implicit persona - the complete persona that embraces both vocal and instrumental components - would also need to explicitly incorporate performative decisions and additions by the author(-performer). Lyric changes, melodic adaptions, gestures, costumes - all the elements that culminate in a live performance contribute to the author's persona that lives within the music and are used by listeners to understand the relationship between author and song. The importance of this aspect of performance speaks to the need for an additional factor to be included in the personae equation presented by Cone.

To better understand the author's presence in the music of singer-songwriters requires a third factor to be paired with Cone's vocal and virtual personae. I put forth an addition I have titled the vital persona. This third factor represents the aspects of the author's persona that are vitalized and actualized through performance by the author. I use the word "vital" for both pragmatic and ideological reasons. "Vital" alludes to a sense of being alive (or "live" as in live performance). This characterizes the performative elements that this new factor encompasses and represents. The title also speaks to this new factor being an integral element of the singer-songwriter genre that is different from other musics in a crucial way. When the vital persona is added to the vocal and virtual personae, one is presented with an implicit persona that speaks more directly to the crossing-over of the multi-layered roles that occur in the music of singer-songwriters. The adaption of Cone's model tailors it to a more performance-centric context that aligns more closely to the phenomenon of voice in popular music, particular the music of singer-songwriters. 


\section{The Implied Author and Vital Persona in Song}

IN THIS RESEARCH, I present two central applications of implied authorship in music, where the author/composer's persona is crafted and subsequently performed. Here I discuss the use of lyrics as tool for both performing authorship and interpreting it, and Chapter Three continues this work by focusing on the voice as conduit for these lyrics, stories, and interpretations. The implied author in song is created and expressed through lyrics, and subsequently in performance. It can be tempting to interpret lyrics as autobiographical representations of the performer, particularly in the case of the singersongwriter, where the performer is also the author. However, even when the narrator in lyrics appears seemingly transparent by interacting with themes that correlate to the performer's life, Booth would argue that it is important to remember that the self presented through these texts is not a replica of the 'flesh-and-blood person.' As Booth notes, 'in every corner of our lives, wherever we speak, or write, we imply a version of our character that we know is quite different from many other selves that are exhibited in our flesh-and-blood world' $(2008,77)$. Booth theorizes that through the crafting of a text, we construct a version of ourselves that, only when added to the other implied personae we share in alterative circumstances, culminates in a direct representation of who we are as a complete person. ${ }^{9}$ These implied selves are highly mediated and edited, despite whatever sense of autobiography is alluded to or presumed. What we are presented with, therefore, is a refined version of the author, a creation that is just as much a product of manipulation and enhancement as any fictional character.

The implied author of the singer-songwriter is an interesting case, as fan engagement so often rests upon the assumption that musicians are performing their personal truths. ${ }^{10}$ However, even in a piece that is heralded by the singer-songwriter as autobiographical, it would be remiss to ignore the editing that has gone into the construction of the work. What listeners are hearing is an edited song, with edited lyrics, that present an edited version of the performer and their reality to audiences. Despite Amanda Palmer telling everyone at the Garret Street concert that "Trout Heart Replica" was written about her experience of seeing the beating trout heart, or Hera's statement on Live At Al's that one song was written about her 'clumsy clumsiness' (2008), both songs

\footnotetext{
${ }^{9}$ This is indicative of Richard Schechner's theory of performance that argues that the 'self perceived by audiences is neither the "actual" author, nor a completely fictional entity. That is to say, the "self one has access to is simultaneously "not-me" and also "not-not-me." See: Richard Schechner's Between Theater and Anthropology (1985).

10 This assumption is revealed through discussions on singer-songwriters in general, as well as in artistspecific discourses, illustrated by Bono's quote on the dust jacket of Amanda Palmer's novel The Art of Asking (2014a), which reads '[Amanda's] capable of anything, incapable of telling anything but the truth.'
} 
have gone through a process of crafting and reworking, culminating in the final product audiences have access to.

Hugh Barker and Yuval Taylor also identify the presence of an implied author in their study on authenticity in popular music, theorizing the implied author as one tied to questions of "being real," noting that

When artists attempt to present their "real selves" to their audience, they must necessarily make some compromises. For a song is almost always a crafted rather than a spontaneous utterance... what separates the artist's real self from the self that is presented to the world we can call "mediation" and the artist who strives to be authentic will try to minimize the level of mediation to the greatest possible degree $(2007,219)$.

In the context of a musical performance, the pairing of authenticity with representations of truthfulness is a catch-22 for audiences as well as musicians. Booth suggests there is no way of representing the whole self within a text, arguing that no matter what version of the author is implied, it will never fully encompass all personae, therefore leaving audiences unsatisfied. Consequently, artists must strive towards the impossible, aiming to present themselves honestly in their work if they wish to gain authenticity, despite the sheer unfeasibility of the task at hand. It seems that a happy medium can be reached when performers are able to be honest enough and audiences believe they are witnessing the "true" author. However, for a value judgment that is so prevalent and contingent on perceptions of honesty and truthfulness, there appears to be more than a dash of falseness lying just beneath the surface.

Combining autobiographical truths with fictional and fantastical elements in song further complicates the search for an author and any endeavors to crystalize the multiple identities of voices found within a text. The juxtaposition of fact and fiction leads to information being understood as true by audiences and fans due to its perceived relationship to "true" facts. As narrative theorist Susan Lanser notes, "both the concept of the implied author and the reading of texts as extensions or embodiments of the historical writer entail attaching to the author the whole of a text' $(2008,211)$. By this theory, information that is deemed truthful comes to impact understandings of the other details in a particular song - true by association, as it were. In an interview in 2014, Hera spoke of weaving autobiographical narratives with fictional elements. When asked how she approached telling "true" stories, she explained,

You definitely spice up the story...I don't feel I need to tell the truth, the whole truth and nothing but the truth in a song. I mean, a lot of it stems from something true or something that happened and because it's such a personal thing and it's me performing it, then I'm generally singing something I believe in or sharing something that I think is important (p.c, 2014). 
Katie Morton also discusses this practice, saying 'I love writing songs because I can be cryptic. I can say things and I know exactly what I mean but I can say them without hurting anyone or being too direct. But I can still find some peace inside myself (p.c, 2014). This process explained by Morton speaks to a manipulation or mystification of reality, where "real" feelings and events are twisted or hidden to facilitate a cryptic retelling. Interviews with these two singer-songwriters reveal what appears to be a common practice in songwriting, which leads to question how fans and listeners could or should go about interpreting the narratives they are hearing. It is not a straightforward process to determine whether the author is sharing an autobiographical story or a fictional one, given the interlacing of the two. To use the inclusion of autobiographical tales as the backbone of a search for the author is complicated, as imaginations can be disguised as truths or hidden amongst pillars of autobiography.

By now, one thing that is abundantly clear is the notion that reception plays a key role in the teasing out of musical meaning. In an essay on reception in musical scenes, Adam Krims claims that audiences create meaning based on the active ways they listen to music. He argues that meaning, far from a fixed or determinable understanding, is defined through individual or collective active engagement, with listeners 'defining and redefining music and appropriating its social values and forms' (Krims, 398, 2009). This defies notions of standardized passive listening that are heralded by Theodor Adorno in early studies of reception and meaning in popular music. These active participants, integral to the development of a scene in Krims' opinion, are also key players in the search for the author that preoccupies so many fan discussions. While performers may make certain decisions that implicate themselves more within their music, such as Amanda Palmer connecting "Trout Heart Replica" to her breakup or Hera telling the audience the song reflects her clumsiness, these performative and compositional decisions are adopted and augmented by listeners, who draw on additional information sourced elsewhere to understand the relationship between the composer, performer, and music.

\section{II: The Influence of Social Media}

SOCIAL MEDIA PLATFORMS have aided the development of various processes of engagement between fans, listeners, and musicians. It is expedient to consider how some of these practices are contributing to the search for an author in song, as this is a habit 
participants in my 2014 e-field research identified as being an integral part of the way they engage with singer-songwriters.

Social media platforms have an array of purposes, each focused on achieving something unique yet all brandishing their collective ability to increase communication and facilitate connections between users. The majority of platforms available to date consist of networking websites (Facebook, Twitter, LinkedIn), video-sharing websites (YouTube, Vimeo), photo-sharing websites (Instagram, Flickr) and music-streaming websites (Spotify, iTunes, Bandcamp). The rise of these various websites and applications and the subsequent development of networks of connections between users encourages wider and more accessible dissemination of information across the globe.

The ability of users of social media platforms to share information with their followers in a fast and accessible way has allowed performers to connect with thousands of people almost instantaneously. These processes can subsequently lead to a destabilization of the boundaries between followers, fans, and friends. In a 2012 article 'Fans or Friends?: Seeing Social Media Audiences as Musicians Do,' Nancy Baym argues that the terminology of Facebook contributes to this collision of concepts, as fans can friend-request a musician, becoming one of their Facebook "friends" despite in a nondigital context being a fan, not a friend. Despite this collision leading to often misleading relationship titles, Baym also proposes that interactions online do facilitate closer personal connections than previously possible between fans and musicians. With musicians posting about their daily lives on mediums that thrive off their ability to disseminate information quickly and effortlessly to large audiences, the previously-thought concrete divide between friends and fans or admirers is disintegrating (Baym, 2012, 302). Amplified social media presence and interaction between listeners and musicians has led to the creation of an illusion of intimacy, where connections online result in heightened perceptions of connection in life offline. This is sustained through perceived direct contact with performers through their social media output. It is further fortified and invigorated by the increased publication of personal details and stories on these platforms: anecdotes on Facebook about the musician; Instagram photos depicting the musician's concerts as well as their day-to-day happenings; Twitter newsfeeds that appear to document the musician's life in a stream-of-conscious style. These techniques give listeners and active followers a chance to "experience" the musician's life, connecting with the musician through the information they have shared online that is often presented in an explicitly personal way. 
The three artists spotlighted in this thesis each govern their own social media profiles, therefore I am not attributing more agency to them than they deserve. Hera acknowledged a difference between intent and reception when others are in charge of an artist's social media, explaining that

If it's a marketing team on board doing stuff on behalf of the artist then it's impersonal and people aren't going to engage with it, so you actually have to believe it to do it, I think...there used to be this thing that you are the artist and no one can reach you and there's no way to get a hold of you and you're all mysterious until you play a show and then whatever else you do is mysterious, but these days I think that barrier is gone and people are more human (p.c, 2014).

Her description illuminates how self-governed social media seems more personal and leads to a breaking down of barriers between musicians and listeners. This breakdown contributes to the listener's sense of being told personal, honest, and real stories by the performer and is additionally mediated through the intimate performance style often used by singer-songwriters. Katie Morton, too, spoke to being in charge of the social media side of music-making, posing the question that 'if you're being yourself, you're more likely to connect with your people, right?' (p.c, 2014). This seems to emphasize the importance of musicians being in control of the social media platforms under their name.

The ability to facilitate communication so instantaneously and continuously on social media platforms appears to be a double-edged sword for every-day users, as well as musicians. While being able to engage easily with others (friends, family, fans and followers alike) is beneficial, it can simultaneously create a feeling of overwhelming pressure to be contactable at all hours for fear of missing important information or being labeled a careless communicator (Hafter, 2009; Volpi, 2012). Most musicians would agree that use of social media is advantageous for promoting music and gaining new listeners, with countless guides and articles published online advising other musicians how to make the most out of social media. ${ }^{11}$ Many musicians also see it as a valuable way of connecting with listeners in a quasi-personal fashion. When discussing her social media usage, Hera, says 'I often share like little life-y things, like my cats and if I do something stupid, which tends to be quite often. It's nice to have a place to vent about just everyday things' (p.c, 2014). However, for others, the regular communication and energy demanded by maintaining a continuous presence online can be draining and outweigh the potential positives of such practices. In our interview Morton spoke of the inherent difficulty of sustaining a good online presence while also being an introvert.

\footnotetext{
11 An example of this is '25 Social Media Resources for Musicians' (2013) uploaded on Music Think Tank, available at http://www.musicthinktank.com/mtt-open/25-social-media-resources-for-musicians.html
} 
When I feel the connection starting to happen, it exhausts me very quickly. It really depletes my energies so I have found that the more active I am with it, the less energy I have for creating stuff in the first place, so I actually have to switch it off unfortunately. And I feel like that's very unfortunate for me because social media is one of the best ways of connecting with people these days. So struggling with it is not ideal (p.c, 2014).

Highlighting the complex nature of social media interaction, Morton identifies that struggling with this sort of communication is detrimental in a society that expects people, especially musicians, to be regularly active online.

While it is not new for listeners or fans to seek information about a particular performer, as seen through subscription mailing lists, record clubs, and fanzines, the rise of social media platforms has allowed this information to travel further faster, reaching more users easily, and opening the doors to more interpretive practices developing. In a recent interview, Palmer acknowledges the relationship between changes in the media and perceptions of artists, saying that 'uncovering layers of artists and uncovering layers of process and meaning' are both aided by new media and explained that

[In the] old media, you pretty much got one big perspective on things and then if you were really interested you could dig underneath, or if you knew people you could dig underneath; and now everyone is able to view things on multiple levels (Palmer, 2014c).

Palmer's reference to 'multiple levels' refers both to the amount of information people are able to access through new media platforms, with macro-level and micro-level understandings of certain events or songs, and also to the uncovering of multiple layers of particular people and artists. Listeners often pride themselves on their ability to discover information about musicians and to learn about individual songs or albums, as well as having a more in-depth knowledge of the performer "as a person." With more and more information being made available online by performers, their respective social media personnel, and the paparazzi, there is a treasure chest of materials and resources for listeners to negotiate when searching for an enhanced understanding of a specific song or musician.

Within the context of social media platforms, a variety of interpretive practices and interpretive communities have arisen, connected to the music industry in general, as well as those associated specifically with a particular musician, band, or genre. Listening is celebrated as an active process, whereby the author(-performer)'s role within the musical narrative is extended and interpreted by a listener who brings with them their own subjective ear and set of experiences. As seen through the previous discussion of banter, listeners eagerly latch onto information provided by the performer and use this to supplement their interpretation of the music, actively expanding what they think the song 
means by referencing what they have been told. The combination of these two techniques - one engendered through actively engaging with information imparted by a performer, the other developed through independent (or at times, collective) seeking of information in an array of contexts - leads to a multiplicity of meanings being created and disseminated in regards to a single piece of music.

\section{Active Engagement and Webs of Associations}

THE INTERPRETIVE SCHEMA developed by Daniel Cavicchi in his ethnography of Bruce Springsteen fans is a particular model of listener engagement that contributes to this growing deliberation on the methods listeners utilize to contextualize a piece of music. As discussed in Chapter One, Cavicchi's model identifies five distinct sets of associations that manifest in a particular musical interpretation. Summary associations developed through perceived connections to other songs and albums by the same artist, and aesthetic associations that are sustained through musical elements that reflect the expectational sets listeners have of specific genres, combine to create interpretations based on other musical worlds. Cavicchi's third phase of interpretation, political associations, moves away from purely musical considerations, and illustrates listeners' attempts to link the artist's ideologies to those views, opinions, and narratives expressed in the music. A broader conceptualization of the political facet of interpretation is Cavicchi's fourth set of associations, called the biographical associations. Biographical associations function analogously to political associations, as they are both sustained through listeners finding links (either implicit or explicit, real or supposed) between an artist's life and the stories that are portrayed and highlighted within their music. Cavicchi identifies personal associations as the final method of interpretation, which encapsulates listeners "finding" themselves in the music through identification with the music's narrative and primary emotions.

Of these five steps of interpretation, one commonly evoked by fans and listeners of singer-songwriters is the process of using the artist's life to better understand the artist's musical output. Cavicchi describes this process in relation to Bruce Springsteen in more detail, noting that

Fans often see Springsteen's music as quite personal, a form of communication about his experiences, feelings and thoughts. Springsteen's references to actual places and people in his songs, and especially his long, rambling introductions about growing up and his feelings about the state of the country during live performances, have only reinforced this perception. Appropriately, many fans interpret Springsteen's music in terms of how it relates to what they know about the circumstances of Springsteen's life $(1996,216)$. 
Cavicchi's assessment of how fans interpret Springsteen's music is important in light of the fact this practice is not unique to this one artist. Remarkably, despite the dominance of this method in practice, little has been written about it in theory. As noted by Nicola Dibben, 'given the centrality of emotional authenticity to musical reception, surprisingly little scholarly attention has been given to analysis of the relationship between artistic biography and its mediation through popular music' (2009, 151). The techniques and interpretive practices identified by Cavicchi run through conversations on a variety of musicians and in particular, singer-songwriters. Cavicchi emphasizes two key techniques utilized by Springsteen himself that influence perceptions of biographical honesty in his music that are important to wider discussions of music and/as biography: the inclusion of actual places and people in musical narratives and the presence of stage banter used in live performances as a means of introducing songs. Banter plays a vital role in the amplification of biographical associations and is also tied closely to the singer-songwriter genre and tradition, as seen in Chapter One. It is a critical way that communication and connection are facilitated between a singer and listeners, and plays a crucial role in broader interpretive practices.

It's a "Fan" Thing

THE USE OF THESE METHODS of interpretation as a tool for connecting with music and musicians are echoed through anonymous responses I received to an online survey I conducted in September 2014 that examined popular music and fan engagement. This survey helped to bring my work back to what listeners and fans think and do - an important theme in my research and a key methodology driving my research. The 80 participants, who were between the ages of 18-50 and were contacted via Facebook and Twitter, were asked to discuss what being a fan meant to them and to draw on their own experiences to explore how self-identifying in this way may have influenced or changed their listening practices. An overwhelming number of responses came back explaining that the transformation from casual listener to fan is marked by a move to more "active" listening. While a few respondents noted strictly "musical" ways this type of listening is actualized, with a focus on studying how the musician plays their instrument or thinking about 'understanding how the music [is] layered and made,' the majority of responses were concerned with making links between performer, author, and song, echoing the connections cited under Cavicchi's practice of biographical associations. For the survey respondents who did not indicate that they used interpretive practices that built off 
biographical associations or connections between performer/author/song, their exclusion of this practice in their answer is not necessarily evidence of it not occurring in their repertoire of listening habits. I asked them if their listening habits had changed since becoming a fan of a particular artist. For those that responded that their habits had remained consistent, they did not indicate what their habits were to begin with. This therefore means that some of these respondents may still be utilizing these habits of biographical associations even though they did not explicitly state as such.

It is curious to note that a vast majority of the musicians named by participants in relation to these biographically-motivated interpretive practices were singer-songwriters (such as Ed Sheeran and Taylor Swift), as this supports the hypothesis outlined in Chapter One that biographical associations are a common thread running through the expectational set of the singer-songwriter. Sentiments on the issue raised by survey respondents can be categorized into two main phases, which work in tandem with one another and culminate in the creation and perpetuation of a key interpretive practice in popular music. The first phase of this interpretive practice as indicated by respondents is characterized by the listener's interest in the musician's life, outside of simply knowing the names of albums or individual tracks. One respondent described it as "knowing details about the artist and following their history'; while another explained that being a fan meant 'being invested in a particular artist and their going-ons, musical and otherwise.' Another respondent explained that being a fan meant they have 'become more involved in that musician's life...I research their background and look into their life a lot more than I normally would.' The respondent noted that this has led to 'feeling more of a connection as you know what the songs are about.' Not all respondents identified this trait of biographical questing in such a positive light, however. One rather scathing reflection read, 'a fan is someone who obsesses over the personality as much if not more than the actual music.'

The second phase of the interpretive practice of biographical associations relies on establishing connections (both implicit and explicit) between information sourced and understood about the musician, and the music they produce. Building off the methods utilized by listeners in phase one, this practice incorporates further examples of "active listening" where listeners vigorously search for ways to understand a piece of music in light of its relationship to the author(-performer) figure. Nearly all survey responses identifying this practice were concerned with lyrical content, thinking about how themes and narratives within songs may (or do) reflect the musician's life. This general practice 
of understanding music in light of understanding the musician is illustrated by one participant who stated: 'when you know the background of a musician and you follow what they do you can find more meaning in the musician's music.' Further remarks exemplifying this practice included 'understanding their history can make the words make more sense' and 'being a fan you kind of know more about the musician as in personal facts/events so you can know where they are coming from when they wrote it [their music].'

A number of sub-themes flowed through the responses on biographical associations, elucidating how this broader practice manifests in a variety of ways. One such identified custom was the process of repeated listenings, which led to thinking about the motivations musicians have for writing a particular piece and how the lyrics may reflect the musician's life and/or intentions. This practice was discussed by one survey respondent who commented that 'I find the more I listen to a song, the more likely I am to think more about the lyrics, what they mean, and why the musician wrote the song.' It seems here that there is a tacit assumption that the lyrics and their "meaning" are connected somehow to the musician's life, the "why" of the musician realized through the lyrical content of the song.

A specific actualization of this assumption is the practice of tying the performer directly to the lyrics and the song's narratives. This practice primarily involves identifying ways that a song reflects or responds to the performer's life - and in the case of the singer-songwriter, the author(-performer)'s life. One respondent noted that as they became more involved with a specific performer they 'paid more attention [to the music] and have been drawn deeper into the meanings of lyrics and the tone of the music, been intrigued and moved to investigate. It's like reading a mini-biography.' The evoked parallel between reading a biography and listening to a song is striking, and conjures images of an extremely personal connection between song and performer. I will return to this point later in this chapter in light of questions of linguistic paradigms and first person narratives. Another survey participant stated that 'through listening to artists such as Ed Sheeran and Taylor Swift I have been able to compare and contrast lyrics and how they relate to different aspects of their lives' and they went on to say that this has made them want to 'widen [their] musical tastes to see how other artists have done the same.' The desire to extend this practice to other performers speaks to the value listeners attach to these methods of engagement and how they find it a rewarding way to actively listen. 
A further sub-theme that emerged from my e-field research was the importance of practices of personalization in performance. Highlighting key methods of communication in performance settings and promotional music materials, one respondent wrote that

In particular with Ed Sheeran and Taylor Swift - these artists take the time to pour their hears out into these songs, explain their original meanings, and how they feel when they release songs to the fans. If you can put a story to the lyrics, or understand why they put a certain guitar riff into a specific part of a song, it just makes it that much easier to personally connect to the artist and song.

This passage is important as it highlights not only a number of practices that lead to a more in-depth understanding of a particular piece of music, but it also suggests that these practices and this deeper understanding lead to feelings of connection between listener, artist, and song. It also insinuates that performers who share stories - in song, in person, and those shared in person that appear to be unequivocally tied to a song - results in greater perceptions of connection and intimacy. At the Garrett Street Collective, as Amanda Palmer shared her story of broken yet beating hearts and trout in barrels, her narrative was functioning on multiple levels. It connected Palmer to her song, implicating herself within the lyrics' narrative. Through this act, she also connected with her audience by evoking a feeling of intimacy. Subsequently, this feeling then impacted how the song's narrative was understood, the perception of honesty of Palmer's supposed confession coloring perceptions of confession-like storytelling within her music.

THE IDEA THAT SONG LYRICS can be read as an extension of the author(-performer)'s autobiography relies on a interpretive transfer, where a listener uses information they have accessed from one arena to understand another. But just as in earlier discussions where I warned of the crafted nature of the self in lyrics, Morton also spoke about this crafting occurring during social media interactions, suggesting that information disseminated online by performers cannot be interpreted as unmediated. Speaking of the challenges of social media, Morton told me that

I think social media is wonderful. I think it does a lot of good, and can be so super helpful. Personally, being such a massive introvert, I find it really really hard to say anything. I will fret about what I'm saying. I can still recall exactly what I've said months ago because I will think about it and then I'll delete it and I'll think about it and have to edit all the grammar. I go crazy. So to me it feels like too much connection because I struggle with introversion anyway (p.c, 2014).

Just as Wayne Booth postulated that in everything we do 'we imply a version of our character' $(2008,77)$, Morton here is speaking of a very similar process. Through extra editing, careful crafting, and deliberate decision-making (for Morton, brought on by 
introverted tendencies), the information, statuses, and narratives shared online challenge the notion that these updates are unmediated and direct.

Therefore, when a listener uses information conveyed online to make sense of lyrical content within an artist's music, the crafted nature of the music needs to be considered in conjunction with the crafted nature of the "causally" conveyed information. This moves the conversation around full circle to think about the relationship between listener and musician as being sustained on an illusion of intimacy. As noted by one survey participant,

Being a fan also means that you have a feeling of "knowing" the musician, even when you in reality probably don't. Consequently, you're more likely to associate a theme or story within the music as relating personally to the artist, even if it has no relationship to the personal artist.

This illusion is not founded on lies - more often than not the information shared is grounded in the truth; but rather than accepting every word as an honest representation of the performer, the stories and updates online should be understood in light of practices of creative-license, just as Hera and Morton indicated that non-fictional stories they tell through song are presented in ways that incorporate imagined elements, pairing reality with creative, fictional enhancements. This juxtaposition is challenging to identify in practice when musicians use first person narratives to tell their stories, appearing to explicitly link themselves to the narratives they share. Both in song and in speech, the linguistic signifier "I" is connected to the immediate speaker more than any other pronoun and consequently, as the following discussion explores, pronoun usage can complicate the already fraught relationships between author(-performer) and song, as well as connections between online, offline, and in-song personae.

\section{III: Who Am "I"?}

\section{I as Function; I as Representation}

IN CONVERSATIONS I HAD with artists, they mentioned some similar interpretive frameworks that were suggested by the participants in my e-field research. Katie Morton noted in our interview that first person narratives are not always indicative of personal stories, despite typical interpretations of I-narratives (that is to say, first person narratives) resting on structures of autobiography. In a discussion of singer-songwriters' compositional practices, Morton elaborated on the various uses of "I", saying

But I think, whoever's singing, especially since we often have music videos that go along with it, the person owns the song and they're saying "I". They're talking about 
themselves. My natural response is to believe that they're singing from their own experience... [however] I use any pronouns. I will tell my personal story from a 'he' or 'she' or 'they' or 'we'. I will tell other people's stories or situations using 'I', and it's not about me. I will personify a feeling into 'I'. I do that quite a lot. I often take an internal struggle that actually doesn't have a face or a name and given it shape as a human kind of thing. So no, pronouns are nothing to go by in my writing. No clue at all (p.c, 2014).

Morton raises here the complex nature of unassigned pronouns, particularly thinking about those associated with first person narratives. ${ }^{12}$ When a pronoun remains unassigned, with no directions or clues that hint at interpreting it as representing an "other" figure, it can be difficult to distinguish between the singer-songwriter and the first person pronouns in the music they produce, due to the tight interlinking of the different roles of musician as lyricist, musician as composer, musician as performer, and musician as narrator. As Palmer, Hera, and Morton are involved in multiple processes of music-making, a link is created between the artist and the songs they make, which leads to a conflation of the "I" of the author/composer and the "I" of the narrator. Of all the pronouns in the English language, the "I" symbolizes the most direct link between the speaker and the words they say. In everyday conversations the use of first person narratives are uncritically assumed to be the conduit for the speaker's personal expression- where "I" is used to unequivocally mean "me". Aaron Fox summarizes ordinary language to consist of three main functions for the pronoun " $\mathrm{I}$ ". The first is used for reporting speech, where it is clear that the "I" represents another person ("And then he said to me, "I'll show you a thing or two."'). The other two usages, however, are firmly tethered to the individual speaker and Fox refers to these as the formulaic and the nonformulaic functions. The formulaic is when the word " $\mathrm{I}$ " is attached to a verb of saying (e.g. 'I'll tell you what'), in which case the listener's focus is on the thing being said in relation to the person saying it. On the other hand, the nonformulaic is present when the word "I" is revealing the "real" self of the speaker and this usage is closely associated with interiority and self-revelation (Fox, 2004, 142). Fox's identification of first person pronouns in everyday speech as representative of a self-revealing interiorized private state indicates one way that first person narratives may be assumed to stem from a singer-songwriter's "real" autobiography. As only one set of pronouns exist to service a wide variety of contexts and functions, it is arguable that expectations of the "I" in

\footnotetext{
${ }^{12}$ A further study on the interpretation of unassigned pronouns in popular music is Tim Murphey's 'The When, Where, and Who of Pop Lyrics.' Interestingly, Murphey suggests that the unassigned "I" allows listeners to embody the role of the narrator, rather than hear the "I" as indicative of the performer's own relationship to the narrative, which was not a practice raised by any of the research participants I worked with.
} 
everyday contexts are subsequently transferred onto interpretive practices used to understand the singer-songwriter genre and music - a shift that grows from a language deficit and leads to an interpretation predicament.

This elision of the "I" of the author(-performer) and "I" of the narrator could therefore be seen as a "default" practice for the interpretation of popular music, particularly that of singer-songwriters. Ronald Lankford Jr. demonstrates this in his discussion of Liz Phair's song "Fuck and Run," where he writes that 'the lyric is both revelatory and told from a first person point of view, giving the impression that there is little separation between Phair and the words of the song' (2010, 58). In a discussion of the early folk blues, Peter Muir writes that

All folk blues are sung in the first person, and there is always the implication that the events, actions and emotions of the song are ones that are happening or have happened, to the singer. So it is with popular blues, which are usually sung in the first person and clearly have the singer as the central protagonists $(2009,39)$.

These two passages suggest that in the analysis of popular music, and specifically popular music that is performed by a solo singer, listeners habitually interpret the use of first person narratives as a means of conveying the singer's autobiography through song. It is arguable that this is motivated not only through the presence of unassigned pronouns. The reason for this collapse between singer and narrator could be seen as also stemming from the presence of the author/composer's body in live musical performance, which invites the listener to understand the " $\mathrm{I}$ " of the performer's spoken introductions as synonymous with the "I" of their lyrics. Moreover, the inclusion of known autobiographical details in lyrics further tempts listeners to interpret the narrative "I" as an extension of the author/composer proper.

It is useful to step back here and consider how first person narratives are examined and interpreted in literature, as we can see literary theorists mirroring the observations made by Lankford and Muir where "I" equals "I". In an exploration of the relationship between an author and his or her text in light of reader interpretations, narrative theorist Brian McHale claims that the connection between first person narratives and perceptions of autobiographical honesty are prevalent in the reception of various literary genres. Writing of poetry, he argues that 'the assumption of autobiographical authenticity, of an identity between the poem's " $I$ " and the poet's self is something like the “default setting” for the lyric poem' (McHale, 2003, 235). In a similar vein, theorist Christine Brooke-Rose proposes that in autobiography one may fuse the narrator and the author. While she does temper this by stating that in every other form of literature 'the narrator is himself a fiction, however close he may be to the author' (1981, 
328), Brooke-Rose's assumption that in autobiography the "I" of the narrator is synonymous with the "I" of the author reveals that "default setting" talked about by McHale, and demonstrated by Lankford and Muir.

Once again, Wayne Booth provides a helpful reminder regarding the usefulness, or applicability, of considering the author's use of first person pronouns as indicative of revealing a privatized interior state. Booth's insistence on the differentiation between the "I"s of an author, implied author, and narrator suggest that these personae are rarely, if ever, representative of the same entity, even in a form such as explicit autobiography. This warning to not collate the "I" of the implied author with the "I" of the real author is further extended upon by narratologist Susan Lanser. Lanser suggests that "the "I" that characterizes literary discourse is always potentially severed from and potentially tethered to the author's "I"” $(2008,211)$ and because of this, one must remain conscious of the fact that any character attached to the " $\mathrm{I}$ " is never a true replica of the person writing, even when the narrator within the text is meant to relate in some shape or form to the "real" author.

While Brooke-Rose argues that the narrator in autobiography is an unambiguous representation of the author proper, Lanser considers this literary form with more nuance, critically examining its common interpretation as a site for truthfulness and zerodistance between author and narrator. She proposes that one of the reasons why Inarratives are so frequently interpreted as autobiographical, both those in explicit autobiographies but also those utilized in other literary forms, is that

Because autobiography and homodiegetic fiction deploy the same range of linguistic practices, the ontological status of most I-narratives cannot be proved by citing any part or even the whole of the text...homodiegetic texts provide no formal index of their status as fiction or fact (Lanser, 2008, 206).

Writing specifically of common interpretations of first person narratives, Lanser goes on to say

Against the demurrals of authors and the onto-logic of narratologists, although we are "entitled" to take fiction as nothing but fiction, I-narrative taunts us with the possibility that the "I" of the fiction has some relation to the author's "I" even when the Icharacter is not also a writer or does not share the author's first name $(2008,207)$.

Lanser raises two important issues here that are pertinent to understanding why conflation of the author's "I" and the narrator's "I" seems to be the most common method of interpretation used in understanding first person narratives. First, Lanser highlights the linguistic crossovers between autobiography and first person fiction, indicating how interpretive practices associated with one literary form become used to engage with another form. This echoes Brooke-Rose, who indicates that autobiographies 
offer a space for confession and honesty, traits that then become expected of the "I" pronoun in a variety of contexts. Secondly, Lanser evaluates how first person narratives create opportunities for readers to link the author with the narrator, no matter how tenuous this link may be and regardless of whether the text invites these sorts of readings, aside from their use of I-narratives.

The framing of the "I" figure within a text furthers the default setting for interpretation of explicitly linking the narrator's "I" with the author's "I." This can be achieved through leaving the "I" unassigned, as discussed earlier in reference to Katie Morton's interview excerpt and supported by Lanser, who writes 'it is easier to attach an unnamed than a named "I" to its author except perhaps when the "I" shares the author's name' $(2008,212)$. The unnamed "I" embraces ambiguity while also encouraging readers to search for a link between the author and narrator and find a persona to attach to the unnamed entity. Moreover, the overt referencing of autobiographical facts and events can tempt readers into assuming the "I" of the narrative is one and the same with the author, as seen in the responses from e-field participants who spoke of understanding lyrics based on understandings of the author(performer).

When one considers the variety of ways readers (and listeners) approach the interpretation of first person narratives, an astute scholar is left with three central potentials for the pronoun "I": the narrator, the implied author, and the actual author. Booth's desire to caution readers away from believing the implied author and/or narrator are true representations of the actual author does not remove the possibility that at times there are close links between the real author and the narrator featured on the pages, and that at times these links are touted by the author themselves. Therefore, when considering I-narratives as autobiographical texts, there is a network of personae and characters to evaluate and navigate. In this way, I look to Edward Cone's notion of multiple, enriched readings to develop a listening prototype that goes some way to encapsulate the differing levels of readings (and listenings!) necessitated by pronouns in popular music.

\section{Listening: A Three-Step Model}

IT IS CLEAR BY NOW that the linguistic possibilities of the pronoun "I" are varied and dynamic, and the interpretive practices that are associated with understanding this pronoun are fraught, further complicated by implicit and explicit cues from the author(performer). What this discussion has revealed is that a more nuanced approach to interpreting first person narratives is required in order to better understand its role in 
negotiating the complicated relationship between author, text, narrator, and performer. I propose that, due to the continuous combining of fact and fiction in the work of singersongwriters and the common practice of re-working autobiography into art, a simple binary of personal/universal narratives is inadequate to describe the complex layering of narratives at play within lyrics. Instead one must look for an alternative way to understand what an "I" might signify. The interweaving of narratives that can be attributed to the author(-performer) and those that are less personal, albeit still possibly connected to the author in one way or another, come together to form a narrative that does not speak to all experiences but may not necessarily only speak to one autobiographical experience.

Therefore, I argue that when navigating the narrative waters of singer-songwriters it would prove advantageous to think of "I" in a more careful and considerate way, where "I" does not always mean just "me", but also does not equate to "all". Drawing on Edward Cone's multi-layered model of reading developed in 'Three Ways of Reading a Detective Story' (1989), I theorize the following three steps as a productive way to navigate through various interpretations of I-narratives in song. As demonstrated by earlier discussions, one can consider the default reading (or first-level reading) of a singersongwriter's use of "I" as a pronoun indicative of autobiography, where the same linguistic paradigms from autobiographical texts are used to convey personal truths unambiguously, resulting in an I-as-author reading and listening. A further two readings of the same text could result in a more nuanced interpretation. A second-level reading, which occurs upon closer inspection on the relationship between content and producer, may attribute the "I" to an entirely "other" persona, one that is fictional and simply exists within an individual text, bound by the framework of the song's introduction and coda. That is to say, I-as-narrator. Finally, a third-level reading is engaged only after considering the "I" as being explicitly personal and then entirely universal. The third-level default of Inarratives associates the "I" with something else, not a specific nor a universal persona, but something in between, where the "I"s function is interpreted as $I$ as both/neither. This third-level default reading is where the apparent discrepancies between fact and fiction can be considered and accepted. It is not a matter of resolving the issues, labeling each element as true or false, for it is this combination of autobiography and imagination that offers musicians a place to experiment and create. Rather, this third reading creates a space where fact and fiction can reside harmoniously, culminating in an "I" that represents neither a solo figure nor a universal collective, but instead a sophisticated 
inbetweener that speaks to an informed audience and speaks for and through a singersongwriter.

This three-step listening model is actualized through the utilization and subsequent interpretation of lyrical and physical voices. In one sense, it relies on the use of voices such as those suggested by Cone in The Composer's Voice. The author/composer's multiple personae that are in action during composition and performance transmit the information that is consequently used by listeners to understand and create musical meaning. This process is augmented by the notion of the vital persona, which acts as the metaphysical "voice" listeners engage with. This listening model is also realized through the use of actual voices. Listeners use the voice that physically produces the sound and lyrics as a conduit for individual and collective interpretations of narrative. This physical voice combines with the composer's voice à la Cone, and together these result in a dynamic collection of personae and producers that influence listener interpretations of music. 


\section{Chapter Three}

\section{What's in a Sigh: Locating the Voice of the Singer-Songwriter ${ }^{13}$}

\section{I: Attentive Listeners}

IN OUR EVERYDAY INTERACTIONS, whether one is speaking, shouting, or singing, the human voice acts as a conveyer of inner thoughts and feelings, growing from the body, emanating through the diaphragm and vocal folds before being transmitted aurally to those who will listen. In musical performance, it is the voice that is nearly ubiquitously tasked with communicating lyrics or text, and frequently listeners' interpretation of music's emotion is mediated through their interpretation and experience of the emotion perceived in the voice of the performer (Dibben, 2009; Frith, 1998). I argue that the coexistence of speech and song in live performance means that frameworks used to understand an individual's relationship to their voice in a spoken context may be used to understand this relationship in song. The prevalence of spoken interludes and introductions in singer-songwriter performances means that interpretations of the voice become a key way in which the music is decoded. Consequently, the voice can be understood as being a significant element of the vital persona's performance jurisdiction.

The role of the voice in performance has been theorized by a number of scholars, and it would be impossible to review them all comprehensively here. I have instead approached this topic selectively, navigating the available materials by focusing on those reflective of the ways the voice is discussed by fans and listeners in everyday arenas. Some of these materials examine musical styles outside of popular music, such as $19^{\text {th }}$ century opera. While it would be erroneous to argue that the functions of the voice in one genre can be mapped exactly onto another one, there are similarities in the way the voice is treated and interpreted across genres and styles, making it worthwhile to study how the voice is being theorized by scholars in the broader field of musicology.

For example, Carolyn Abbate's seminal work on opera examines the crucial relationship between text and voice in operatic performances. In Unsung Voices: Opera and Musical Narrative in the Nineteenth Century, Abbate personifies the voice as 'stubborn' and

\footnotetext{
13 This chapter functions like an amuse-bouche does in a banquet. It offers a small, bite-sized taste of future research endeavors, tantalizing readers with what could come next. I draw on theories presented and developed in previous chapters, but more than that, I also provide a model of how these theories could be used to understand other elements of the singer-songwriter genre and experience. Alternative research paths for these theoretical frameworks are suggested in the concluding chapter.
} 
'insisting upon its privilege,' due to it emanating directly from the body of the performer $(1998,12)$. Edward Cone, also speaking of $19^{\text {th }}$ century European art music, argues for the prominence of the voice in musical texture and reception. In Cone's words, when the voice sings 'it demands to be heard' $(1974,79)$.

Picking up on this in a popular music context, Simon Frith in Performance Rites dedicates a chapter to the voice, thinking about who is speaking and the ways that this speech is conveyed. The dilemma of who is speaking dictated my pervious chapter on persona(e) in music and lyrics, but Frith additionally writes of the voice's privilege, evoking similar paradigms as those used by Abbate and Cone. Frith argues that 'even when treating the voice as an instrument, in short, we come up against the fact that it stands for the person more directly than any other musical device' $(1996,191)$. Just as Abbate conceptualizes the prominence of the voice in listeners' minds due to its audibility in the music and its connection to the body, Frith makes a similar observation by suggesting that the voice is tied more closely to the performer than any instrument. The similarities between Firth's observations and those of Abbate are compelling, given the different musical contexts they emerge from, as it reveals the significance of the voice over a number of years and genres.

This tight linking of the voice with the performer's body provides another piece of the puzzle of I-narrative interpretations. Understanding the voice as being produced by and connected to the physical body of the speaker suggests a correlation between the body of the performer and the stories they tell, as the performer is implicated within the narrative not simply through the words they use but also through the physical effort they make to produce the sound. Their breath gives life to the story and in doing so builds a connection between the body of the performer, the performer's voice, and the narrative they are sharing. The effect of music's "live-ness" results in listeners focusing on the individual performer and their physical connection to the music, which can subsequently morph into interpretations based on emotional and autobiographical connections. There is an illusion that there is no divorce between the author and text during a live performance, strengthened through the evident exertion of the performer to create the music (such as strained singing, visible perspiration, and dyspnea or shortness of breath), as well as the performer's patent efforts to "own" the song (such as lyric changes). By "own" I do not mean in a legal sense; rather, ownership is evoked here as a marker of a unique personal connection between performer and performance. This ownership is both explicit and implicit. It can be as obvious as a performer beginning a performance 
clearly outlining what influenced the song and often implying that the "I" of the narrative is an autobiographical signifier; alternatively, it can manifest more subtly in the performer's distinctive vocal style through their emphasis on certain words, and inclusion of sighs and pauses in songs. These performative elements that emphasize live-ness work in conjunction with other interpretive frameworks favored by listeners, such as those discussed in Chapter Two, and result in a dynamic practice that starts and ends with the performer's individual connection to the music they are performing in a idiosyncratic "live" manner.

\section{The Voice as Gendered Signifier}

ONE OF THE KEY ways the embodiment of the voice influences and informs listener interpretation is through the lens of gender. The voice's ineffable connection to the human body makes it perhaps the most gendered of instruments, and listeners of both speech and song regularly make judgments of a person's character, sex, and gender based on vocality. A banal but telling example of this is that when using the telephone, one frequently determines what sex they believe the caller is based on voice alone, with no visual cues to aid the decision. In music, too, these judgments occur. Writing of opera in 'The Grain of the Voice,' Roland Barthes argues that the grain is the space where language and production meet, and this grain leads to a variety of interpretations. It is the means by which music's expressive quality is understood. Barthes describes the voice of a Russian bass as 'directly the cantor's body, brought to your ears in one and the same movement from deep down in the cavities' $(1977,181) .{ }^{14}$ Popular music scholars have also considered the role vocality plays in the development of musical interpretations of singer-songwriters, particularly in relation to perceptions of gender and discernments of honesty. Certain vocal characteristics are attributed to being either masculine or feminine, and each set of vocalities are heavily laced with cultural and social value judgments over what "makes" a man or woman. Annamaria Cecconi theorizes the voice as "coming from a throat of flesh that is unique, unrepeatable, and, of course, sexed' $(2005,100)$. Suzanne Cusick argues also that the voice is inextricably and regrettably securely tethered to ideas of sex, which map onto interpretations of gender in the ears of listeners (1999, 29). An in-depth discussion of the voice as a conduit for expressions of gender identity is beyond

\footnotetext{
${ }^{14}$ It is interesting that Barthes, after emphasizing the physicality of the voice and its connection to the singer, firmly asserts that the voice is not personal - it does not express anything of the singer's soul. In the singer-songwriter genre, it seems that this understanding of the voice as not personal is subverted or sidelined, as many fans and listeners' interpretations rely heavily on a belief that the voice signifies the "real" emotions of the performer.
} 
the scope of this research, but it is worth mentioning Shana Goldin-Perschbacher's research on the voice, gender, and sexuality. Goldin-Perschbacher boldly navigates through gender politics and feminist theory in her thesis, detailing a number of singers and how they each utilize their voice in ways that conform to and rebel against societal gender norms. One example of such an analysis is of Jeff Buckley, where she describes his vocality as "transgendered." For Goldin-Perschbacher, Buckley's gender transgression grows from the 'vulnerable-sounding voice' he uses to cover songs that not only male, but also female, singers originally performed $(2008,31)$. This, paired with Buckley's ability to transcend the vocal range typically associated with a male singer and his identification with female protagonists and women in general, culminates in a musical performance that defies being categorized as either masculine or feminine - transmitted through a vocality 'that resists identification with a biological sex' (Goldin-Perschbacher, 2008, 35).

This is an interesting pivot to thinking of Palmer, Hera, and Morton. A detailed discussion of their individual vocalities features in the final section of this chapter, but a consideration of their voices as sexed (and gendered) signifiers is worth mentioning now. Amanda Palmer, described by one blogger as having a 'deep and slightly masculine voice,' sings with a range that crosses gender norms, resulting in a sound that fits comfortably in neither a feminine or masculine camp (Rebel Circus, 2014). On the other hand, Hera is typically described in more feminine terms, called 'the cutest thing since really adorable sliced bread' on a Live Journal conversation - a sentiment that is often carried over into interpretations of her music (Live Journal, 2010). However, perceiving voices as gendered is not necessarily an accurate tool of interpretation despite it occurring frequently, and my final performer, Katie Morton, demonstrates this. Morton identifies as genderqueer, which disrupts notions that an individual's voice can accurately represent its speaker's gender. This illustrates just how complicated the relationship is between gender, sex, and voice. It also goes some way to highlight the intricate web of associations and interpretations listeners sift through when engaging with a singer - and when describing what they hear through the language available to them.

\section{II: Allusive, Elusive, and Illusive Vocalities}

\section{The Voice as Edited and (In)describable}

A FURTHER FACTOR of musical performance that contributes to feelings of live-ness and which plays a crucial role in perceptions of author(-performer) honesty is vocality. 
Wishing to speak of the distinctive features of individual voices that make them both unusual and familiar to listeners, scholars find themselves in a challenging position. A lack of specific and widely agreed-upon vocabulary to describe sound creates linguistic difficulties when attempting to discuss certain voices. Roland Barthes bemoans how when language must describe music it fares 'very badly' (1977, 179). Much of the language used is ocularcentric, relying on vocabulary seized from the realm of vision to describe that which is occurring aurally, such as referring to a sound as "bright". As Blesser and Salter recognize, a 'problem with the written history of aural experiences is readily illustrated by the etymology of aural words. Ancient cultures described their auditory experiences in terms of observable external events and objects' $(2007,69) .{ }^{15}$ Because of this, sound is inherently challenging to discuss. A dependence on ocularcentric language not only marginalizes those with visual impairments but also results in using language that does not accurately describe aural events. Ultimately, this paucity of language results in linguistic barriers to precisely describe both sound itself and its effects.

Despite this inherent challenge, a consideration of vocality cannot be avoided in the context of the singer-songwriter due to its prominence in listeners' critiques and interpretations. Privileging lyrics leads to a favoring of the voices that transmit these texts, tethering the two and securing their place as a fundamental component of the singer-songwriter genre and its interpretation.

Emotions portrayed by the voice, despite coming from an internal, personal place (both in the physical and expressive sense) should not be read as being synonymous with "the truth," autobiographical or otherwise. Any emotion articulated vocally is a performance whether it is occurring on stage, in a lecture hall, or at home. In the previous chapter, I considered the dichotomy of the flesh-and-blood persona and the implied author in a discussion of Wayne Booth. Booth's belief that an author's identity is masked through writing and editing is similar to social psychologist Ervin Goffman's examination of identity performances in everyday interactions. In The Presentation of Self in Everyday Life, Goffman argues that every decision made on a day-to-day basis conveys a certain presentation of a person. This presentation is not necessarily false or deceitful but is not an accurate representation of the whole person. Goffman opens his study with a

\footnotetext{
${ }^{15}$ For further conversations on the dominance of ocularcentric language, see Salomé Voegelin's Listening To Noise and Silence: Towards a Philosophy of Sound Art (2010) and Don Ihde's Listening and Voice: Phenomenologies of Sound (2007), as well as Blesser and Salter's Spaces Speak, Are You Listening? (2007) quoted above.
} 
statement that captures the very essence of his work on identity, writing that he shall consider

The way in which the individual in ordinary work situations presents himself and his activity to others, the ways in which he guides and controls the impression they form of him, and the kinds of things he may and may not do while sustaining his performance before them (1956, xi).

That is to say, decisions made by someone during their interactions with other people involve information imparted in highly-controlled ways and shape how that person is perceived by those around them. Goffman notes that a participant can influence others' perception of him or her by what 'the individual says about himself or on documentary evidence he provides as to who and what he is' $(1956,1)$; information that is not unlike that which is imparted in live musical performances, both in the form of verbal cues (spoken, sung, and all manner of expressions in between), and physical cues (gestures, costumes, exertion, and so forth).

To acknowledge these cues as pre-meditated and crafted, rather than instinctual "in the moment" expressions, is not to diminish their power. In fact, that these cues are so effective and considered a vital element of "good" live performance, despite their manufactured origins, speaks to their power, rather than lessens it.

\section{The Voice as Emotional Signifier}

My EARLIER DISCUSSION ON sex and gender that drew on Cecconi, Cusick, and GoldinPerschbacher, while brief, demonstrates the complex nature of the voice and its reception, where it is tied to cultural values and social norms. Perceptions of emotional honesty offer an additional way voices in the music of singer-songwriters are interpreted an interpretive framework sustained on a belief system that the voice acts as an honest conveyor of the performer's interiorized private state. The privileging of emotional honesty in fan discourse justifies its place within my research and I begin this discussion with reference to Björk and Tori Amos; not out of convenience, but because their voices and musical stylings are often mentioned by listeners as similar to Palmer's own music, with Palmer often being referred to by critics as Amos' 'little sister' (Dahlen, 2004).

In her 2009 study of Björk, Nicola Dibben describes how reception of the singer's music often circles around interpretations of "true" expressions of emotion. Dibben asserts that the connotations of "naturalness" signified by Björk's voice are an essential factor of the reception of Björk's music, as her "imperfect" and "natural" voice comes to represent in the ears of listeners and critics Björk's Icelandic heritage and her musical and emotional honesty. Dibben writes that 'the lack of obvious vocal training... embodies the 
idea of unmediated expression, what the fan refers to as "totally direct" and "authentic" expression' $(2009,144)$. This passage points to the fastening of vocal techniques to interpretations of honesty, a practice prevalent in discussions beyond those associated with Björk.

Emotional honesty as articulated by and contingent on vocality is featured also in Bonnie Gordon's article on the singer-songwriter Tori Amos. In a harrowing exploration of the personal connection between Amos and her song "Me and a Gun," Gordon argues for an extremely personal relationship between the voice and self, suggesting that its significance and appropriateness for expressing truths in song is due in part to how the voice is used as a means of self-expression on a daily basis. Gordon explains it thus:

"Me and a Gun" performs a quest for voice and a desire to make accessible very interior sensations and feelings. It realizes the potential of the singing voice to envoice and thus reveal realms of human experience and subjectivity that usually remain beyond the limits of sensibility. The voice can move along such an axis because it emerges from the physical body, serving as a vehicle for self-expression, identity formation, and interaction with others. It also points inwards to realms that cannot be expressed by language and thus cannot be explicitly communicated, making knowable experiences and sensations that otherwise remain completely elusive. The voice is at once material - of the body in the form of air and breath - and immaterial in that it is not something we can touch $(2004,188)$.

The extremely personal message of the song, expressed through a starkly isolated unaccompanied vocal line, paints Amos' voice as a channel for her inner thoughts and feelings, delivering her lived experience of sexual assault to the listeners directly and without mediation. Musicologist Mary Greitzer identifies "Me and a Gun” as 'stark, intimate, and raw' and argues that these qualities are sustained through Amos' vocality, which invites the listener to focus on the first person narrative $(2007,28)$. The author evokes paradigms of emotional honesty throughout her discussion of Amos, frequently emphasizing Amos' voice as the reason the song is so haunting and "real". Greitzer writes of Amos that 'she demands our attention immediately: this is raw, this is real $(2007,28)$. The author's insistence on the "realness" of Amos' story refers both to the autobiographical nature of the narrative, as well as the a cappella rough vocality Amos utilizes, giving the impression of an intimate retelling of a deeply personal event through an unmediated process.

These accounts of the voice as conduit for sex and gender and emotional honesty reveal the rich array of connotations listeners have of certain voices. Voices are heard as signifying various states of mind, emotions, feelings, and characteristics; no voice is neutral but in the same breath, all voices are experienced in a unique and individualized way. In the following section I discuss how listeners interpret the voices of Palmer, Hera, 
and Morton, illuminating the physical, emotional, biographical and aural connections listeners make based off of the performers' voices and their respective vocalities.

\section{III: Authentic Sounds}

A RECURRENT THEME throughout this thesis has been the challenges scholars inherit through language, particularly when it comes to the function and interpretation of words in cultural and social settings. A final troublesome terminology that is used by music fans, critics, and scholars alike must be discussed at this point due to its prominence in discussions on the voice and vocality: the multifaceted and complex term "authenticity". The groundwork for this discussion was laid in the opening chapter, where I set out some of the ways authenticity appears in popular music - authenticity as promised by performers and retailers, judged by listeners and fans, and critiqued by scholars and critics. What follows is a more focused discussion of authenticity in relation to emotional honesty as conveyed through the voice.

The key difficulty of the term authenticity is the host of social and value judgments imbedded within it, yet its existence with no singular definition. However it is expedient to mention authenticity when discussing interpretations of singer-songwriters' vocality, due to the frequency with which this terminology is utilized already to describe certain voices or the cultural frameworks these voices represent. Having already indulged in a thorough discussion of the various ways authenticity appears in conversations on contemporary popular music, I wish to only bring back those pertinent to this conversation on vocality, in particular Gilmore and Pine's category of the "natural authenticity" and Moore's "authenticity as expression". Both of these understandings draw on performative acts that emphasize "realness" through transmitting raw expression.

We have already witnessed this in the way Greitzer identified Tori Amos' voice as unmediated and raw, resulting in readings of personal authenticity, as well as in the natural authenticity attributed to Björk's eccentric voice that is 'central to perceptions of her as an authentic, emotionally expressive artist' (Dibben, 2009, 109). Similarly, in his discussion of Australian country music, ethnomusicologist Graeme Smith argues that the "natural voice" encourages "familiar ways of establishing the relationship between performer and listener, a poetics of de- and re-naturalization on which the assertion of authenticity in address and meaning is based' $(2011,31)$. 
In the discussions surrounding the three musicians featured throughout this research, their individual vocalities are also frequently described using language that draws on perceptions of authenticity, either directly or indirectly.

For Amanda Palmer one of the main reasons listeners are drawn to her voice is the same reason many are turned away from it. Her rough vocality, edging on out-oftune-ness enchants as much as it annoys. Palmer's music's signature is the strained, unpolished quality of both her piano-playing and vocal techniques, and they speak to a natural, unedited expression of self. Blogger From A High Horse featured a review of Palmer's latest album Theatre Is Evil (2012), describing the song "Trout Heart Replica” as 'accentuated with claustrophobically close string lines and Palmer's raw voice, shifting less than seamlessly between registers and ranges' (Laura, 2012). Another blogger describes Palmer's voice in Theatre Is Evil as 'raw, her voice cracks, but that's the beauty of it. She's not afraid to let her voice convey as much emotion as her lyrics' (Little Bastard, 2012). Josh Eiserike in his review of Who Killed Amanda Palmer comments that 'it's a simple, raw sound with aggressive vocals, intensely personal lyrics and drums that can carry an entire orchestra if they had to' (2008). Eiserike's description is especially interesting as it places conceptions of natural authenticity (raw sounds, aggressive vocals) in conjunction with personal authenticity (intensely personal lyrics), explicitly linking the sound of Palmer's music to signifiers of honesty and authenticity. These descriptions mirror the experiences I have had in hearing Palmer perform live, her voice just as likely to effortlessly reach a note as crack dramatically on the way, a sense of "real" unmediated emotion expressed through the vocals, not simply in song but also in her spoken introductions. Just as Björk was praised for her natural voice by fans who read it as a means of experiencing the "true" Björk, fans of Palmer hear her voice as raw and real, a marker of natural authenticity that subsequently influences their perception of performer-as-narrator, and as a result, their own narrative experiences of her music. Listeners hear Palmer's voice as signifying the very natural and "authentic" flavor of her work, reflecting and influencing interpretations of narrative that play into the variety of interpretive practices described throughout this thesis. In this way, understanding vocality is one step in a "choose your own adventure" novel. It encourages listeners to take a certain path depending on their interpretation of the singer's vocality, which in turn influences how they interpret the other elements of the singer's music and performance.

Hera sings quite differently from Amanda Palmer. However, despite this contrasting vocality, her voice is also described in terms that reflect and evoke perceived 
authenticity. Hera's voice has a sweet naiveté to it, and in performance, her songs are often interspersed with giggles and introduced with softly-spoken remarks. Published criticism on Hera is sparse, but that which does exist includes vocabulary emphasizing familiarity and friendliness, with one blogger describing her as personable and charming (Buist, 2009). In an interview published in the New Zealand magazine Your Weekend, Hera described her own style as 'laid back' and went on to qualify this, explaining 'my sound is just what comes out and feels natural' (as cited in Suckling, 2009). This quote draws on perceptions of naturalness, which in music is often synonymous with understandings of authenticity and honesty, as seen in preceding discussions of Björk. In this same article, Hera confesses that her performances are like 'telling people your deepest, darkest secrets,' further promoting the idea that her natural and soft vocality is a conveyor of truth, sharing secrets and confessions to the audience. Certainly the first time I heard her perform at Bar Bodega in 2010 it felt as if she transformed the rowdy bar into an intimate living room, her gentle voice, hushed whispers, and laughter permeated the space and confessed personal truths to those in attendance. Despite these vocal characteristics being light-years away from Palmer's rough vocality, Hera's voice plays into frameworks that privilege authenticity. At the 2010 concert in Wellington, the sweet innocence of her voice- an innocence that remained even when she was cussing or telling risqué stories was interpreted by those in the audience as evidence of her honest expression. Those around me remarked that her apparent youthfulness lead to feelings of intimacy and friendliness, and the combination of these vocal characteristics culminated in perceptions of emotional authenticity.

Perceptions of honesty are also implicated in the reception of Katie Morton's voice. Morton's voice is hushed and intimate, as if every word being spoken is a secret shared. In performances, both live and recorded, the vocal line is given space to move and resound, not crowded by the instrumental parts. This allows direct and clear understanding of the lyrics and also strengthens connections to the singer. Allan Moore's "authenticity of expression" is described as arising when the performer 'succeeds in conveying the impression that his/her utterance is one of integrity' and that it communicates in 'an unmediated form' $(2002,214)$. This is achieved for Morton through whispered words and intimate intonations, delivering a message that speaks to a perceived authentic personal truth. 
THESE THREE PERFORMERS have markedly different voices, the techniques used and favored by each quite unique and resulting in an idiosyncratic vocality that is decidedly theirs. Nevertheless, their vocalities are all frequently interpreted through a lens of authenticity, with listeners determining the "realness" of both their actions and their music through their voices, where sounds of struggle, sweetness, and secrecy, all hold connotations of authentic unmediated truths.

Furthermore, listeners' interpretations of vocality draw on the narratives the voice is sharing and the wealth of information these listeners may already know of the performer. Rather than acting as an independent factor, vocality is evaluated in conjunction with these other elements of performance - elements that alongside vocality culminate in the vital persona. These come together in the ears of listeners into a dynamic understanding of the performer's relationship to the text they are singing, the narrative they are sharing, and the quartet of mind-body-voice-text at play in any performance.

The authenticity and honesty associated with the voice is grappled with alongside the honesty read into the narrative; one is augmented by the other, where the emotional authenticity heard in the voice increases the authenticity perceived in the story and vice versa. The dynamic and multi-layered practices used by listeners to understand performers' individual vocalities is an important stage in the interpretation of the music of singer-songwriters, particularly due to its influence of perceptions of narratives as emotionally honest and "authentic." It represents a crucial method in how the multiple personae represented by an " $\mathrm{I}$ " in text and in song are understood in relation to the author who wrote it, the performer who sings it, the body who produces it and the vital persona who conveys it. 


\section{Coda}

\section{I: Reflections on the Past, Present, and Future}

AtTending Amanda Palmer's concert at Bar Bodega in 2010 sent me on a whirlwind journey - academically, musically, personally; a journey that sparked new friendships and led to the development of a series of research questions that formed the start of this thesis. I was intrigued by the role vocality plays in the understanding (or creation) of meaning when I heard Amanda Palmer perform live with her bold voice and matching personality. This interest is woven through this thesis, particularly in the two elements of the singer-songwriter performance frame that I have examined in detail - banter and vocality. Through a consideration of how these two elements influence interpretations of I-narratives, I have argued that they are prominent in the expectations listeners bring to the music of singer-songwriters, the relationship between this music and the artists who compose and perform it, and to the broader conceptualization of the singer-songwriter genre. My focus has been to draw attention to the discursive and interpretive practices already in use by fans and listeners, and in doing so I emphasize the wealth of knowledge and array of dynamic experiences of those engaging with singer-songwriters in $\mathrm{New}$ Zealand and around the world. Drawing on existing scholarly literature in popular music studies, narrative theory, and on my own work in digital ethnography, I argue that layers of information - written, spoken, and sung - inform listeners' readings (and hearings) of narrative, particularly in regards to the performers' relationship to the lyrics and stories they share. This research both begins and ends in the language used by other listeners to describe their experiences of singer-songwriters' performances. The questions I asked and the research paths I took were motivated by, and chosen in light of, what listeners, fans, and musicians were already saying. In turn, the theoretical work undertaken responds to, and also clarifies, the discussions already occurring in listener discourse, allowing me to plug these theories into conversations with listeners and performers alike.

Undertaking research in this field has been equal parts fruitful, exciting, and optimistically ambitious, and as such there are still areas left unexamined that form an integral part of the music of singer-songwriters. Due to the multilayered and multifaceted nature of live performance, there remain elements of the physical, aural, and virtual worlds of singer-songwriters to explore in light of the interpretive frameworks discussed throughout this thesis. 
One possible path for further research could be in the realm of gestural analysis, where macro- and micro-level analyses of physical actions could reveal how gestures act in counterpoint with musical output. At the Garrett Street Collective, after Amanda Palmer shared her inspiration for "Trout Heart Replica," her body rolled forward over the piano as if wrought with grief. Only her fingers kept moving, beating out the claustrophobic piano motif; once again providing a musical backdrop for her lived experience that would soon transform into the accompaniment for her pseudoautobiographical song. This gesture, one of many incorporated into performances by singer-songwriters, demonstrates a possible connection between body, song, and interpretation, and could be explored alongside audience experiences.

One could also examine the effect of different costumes or outfits on perceptions of honesty in music. Could Amanda Palmer's physically revealing clothes be seen as a reflection of her emotionally-revealing performance style? Or perhaps Hera's sweet, yet unadorned, fashions could be interpreted as indicative of her unadorned and unmediated story-telling model? Furthermore, how might Hera's drawn-on face art that is often interpreted as being a permanent facial tattoo influence interpretations of her as a performer and her as a person? These research avenues consider perceptions of performers physically embodying their musical narratives and link to the interpretive frameworks discussed throughout this thesis which privilege having the person who writes the lyrics also physically present on stage singing them.

The performative elements mentioned above grow from my extrapolation of Cone's author equation and are reflective of the vital persona's jurisdiction, as they represent the characteristics of the composer that are actualized through performance by the author(-performer). The centrality of Cone's theory to my thesis, as well as its significance to the identified future research avenues, highlights one way the research I have undertaken contributes to broader musicological and narrative discourse. My methodological transposition and transformation of Cone's original model through the addition of the vital persona reveals both the ways in which Cone's ideas are empowering and also how they fall short in describing the complex web of personae that listeners use to understand musical narratives. By extrapolating upon Cone's model, I highlight the central role the body plays in listeners' experiences of contemporary singer-songwriter performances. In particular, I reveal how the body's presence and subsequent actions actively influence listeners' interpretations of I-narratives. The refreshed equation of the vocal, virtual, and vital culminates in a more accurate depiction of the elements at work 
in a live performance by a singer-songwriter. This is particularly pertinent in relation to recognizing the role "live-ness" plays in interpretive practices by listeners, where the body of the performer is implicated in the physical act of performing, as well as the multifaceted act of narrating. Furthermore, my extended model gives agency to fans and listeners, by revealing - and helping to explain - their dynamic and unique practices of interpretive engagement.

This research additionally reveals the rich and dynamic roles voices play in everyday and performative contexts through their physical and metaphysical embodiments. In the interpretive practices highlighted throughout this thesis, these processes both begin and end with the voice - the voice as author's persona, the voice as singer, the voice as mediator. The multiplicity of voices acknowledged by Simon Frith within any performance of a song extends beyond the "performance frame" to encompass the actual and perceived voices that contribute to the musical performance through academic and vernacular discourse. Voices not only transmit lyrics and share stories - they also interpret narratives and inform subsequent discussions, which are continued through the use of the voice both in online and offline contexts. The importance of these various manifestations of voices to this research is demonstrated through the significance of fan and listener discourse to understandings of popular music, of singer-songwriters, and to the creation and perpetuation of genre expectational sets that ultimately suffuse formal and informal discussions of this music. The inclusion of interviews with Hera Hjartardóttir and Katie Morton, and the prioritization of ethnographic methods and efield research participants, directed my work by focusing on the voices already talking about this field of music-making. These voices were supplemented by my own - as a fan, performer, and scholar. Through talking with others and critically reflecting on my own personal experiences, the impact of voices and personae on listener engagement with music was evident. Voices sing; voices speak; voices matter.

When Amanda Palmer Performed on the piano at the Garrett Street Collective, the opening words to "Trout Heart Replica" echoed around the room: 'they've been circling. They've been circling since the day they were born.' Listening to these words at that time, I was struck by how similar they were to the conversations I was engaged with in my academic pursuits. The presence of theoretical tautologies was on my mind and I was intrigued by how these related to the interpretive methods used by listeners to engage with singer-songwriters. In this instance, Amanda Palmer's words echoed my theoretical 
explorations, and once again tied live performance back to my academic studies. And just as the trout's heart in Palmer's song continued beating long after its initial journey had ended, I hope that the heart of this research will do the same, continuing to "live" in the minds of those who read it and the conversations it contributes to for years to come. 


\section{Reference List}

Abbate, C. (1998). Unsung Voices: Opera and Musical Narrative in the Nineteenth Century.

Princeton: Princeton University Press.

Barker, H., \& Taylor, Y. (2007). Faking It: The Quest for Authenticity in Popular Music. New York: W. W. Norton \& Company.

Barthes, R. (1977) Image-Music-Text (S. Heath, Trans.) New York: Hill and Wang.

Baym, N. (2012). Fans or Friends?: Seeing social media audiences as musicians do. Journal of Audience \& Reception Studies 9/2. 286-316.

Berger, K. (2000). A Theory of Art. New York: Oxford University Press.

Bernstein, J. A. (Ed.). (2004). Women's Voices Across Musical Worlds. Boston: Northeastern University Press.

Blesser, B., \& Salter, L-R. (2007). Spaces Speak, Are You Listening? Experiencing Aural Architecture. Massachusetts: Massachusetts Institute of Technology.

Booth, W. C. (1983). The Rhetoric of Fiction: Second Edition. Chicago: University of Chicago Press. (2008). Resurrection of the Implied Author: Why Bother? In Phelan, James \& Peter J Rabinowtiz (Eds.) A Companion to Narrative Theory (pp. 75-88). Massachusetts: Blackwell Publishing Limited.

Brooke-Rose, C. (1981). A Rhetoric of the Unreal: Studies in Narrative and Structure, especially of the Fantastic. New York: Cambridge University Press.

Buist, G. (2009, July 25). Hera Hjartardóttir at the Fringe Bar. Retrieved from http:/ grantbuist.com/2009/07/25/hera-hjartardottir-at-the-fringe-bar/ 
Cavicchi, D. (1996). Tramps Like Us: Music and Meaning Among Springsteen Fans.

(Unpublished doctoral dissertation). Brown University, Providence, RI.

Cecconi, A. (2005). Theorizing Gender, Culture, and Music. Women and Music: A Journal of Gender and Culture 9/1. 99-105.

Cohen, S. (1993). Ethnography and Popular Music Studies. Popular Music 12/2. 123-138.

Colt, J. (Ed.). (2006). Bob Dylan: The Essential Interviews. New York: Wenner Books.

Cone, E. T. (1974). The Composer's Voice. Berkeley: University of California Press.

(1989). Three Ways of Reading a Detective Story - Or a Brahms Intermezzo.

In Morgan, Robert P. (Ed.) Music: A View From Delft, Selected Essays (pp. 77-93). Chicago: University of Chicago Press.

Cook, N. (2001). Between Process and Product: Music and/as Performance. The Online Journal for the Society of Music Theory 7/2, Retrieved from

http://www.mtosmt.org/issues/mto.01.7.2/mto.01.7.2.cook.html

Culler, J. (2000). Literary Theory: A Very Short Introduction. New York: Oxford University Press.

Cusick, S. (1999). On Musical Performances of Gender and Sex. In Barkin, Elaine \& Lydia Hamessley (Eds.) Audible Traces: Gender Identity and Music (pp. 25-48). Zürich: Carciofoli Verlagshaus.

Dahlen, C. (2004, February 19). The Dresden Dolls. Retrieved from http://pitchfork.com/reviews/albums/2452-dresden-dolls/

Davis, F. (1995). The History of the Blues: The Roots, The Music, The People. New York: Hyperion.

Dibben, N. (2009). Björk. Bloomington: Indiana University Press. 
Eiserike, J. (2008, September 19). My 'Who Killed Amanda Palmer' Review. Retrieved from http://www.josheiserike.com/my-who-killed-amanda-palmer-review/

Fabbri, F. (1982). A Theory of Musical Genres: Two Applications. In Horn, David \& Philip Tagg (Eds.) Popular Music Perspectives (pp. 52-81). Exeter: International Association for the Study of Popular Music.

Finnegan, R. (1989). The Hidden Musicians: Music-Making in an English Town. Cambridge: Cambridge University Press.

Fish, S. (1980). Is There a Text in This Class? The Authority of Interpretive Communities. Massachusetts: Harvard University Press.

Fox, A. (2004). Real Country: Music and Language in Working-Class Culture. Durham: Duke University Press.

Frith, S., \& Goodwin, A. (1990). On Record: Rock, Pop, \& The Written Word. New York: Pantheon Books.

Frith, S. (1998). Performing Rites: The V alue Problem in Cultural Studies. Massachusetts: Harvard University Press.

Gender Neutral Pronoun Blog. (2010, January 24). The Need for a Gender-Neutral Pronoun. Retrieved from http://genderneutralpronoun.wordpress.com

Gilmore, J., \& Pine II, B. J. (2007). Authenticity: What Consumers Really Want. Boston: Harvard Business School Press.

Goffman, E. (1956). The Presentation of Self in Everyday Life. New York: Anchor Books.

Goldin-Perschbacher, S. (2008). Sexuality, Listening and Intimacy: Gender Transgression in Popular Music, 1993-2008. (Unpublished doctoral dissertation). University of Virginia, Charlottesive, VA. 
Gordon, B. (2004). Tori Amos's Inner Voices. In Bernstein, Jane A. (Ed.), Women's Voices Across Musical Worlds (pp. 187-207). Boston: Northeastern University Press.

Gracyk, T. (2001). It Wanna Be Me: Rock Music \& The Politics of Identity. Philadelphia: Temple University Press.

Greitzer, M. (2007). Tormented Voices. (Unpublished doctoral dissertation). Harvard University, Cambridge, $M A$.

Hafter, K. (2009, May 25). Texting May Be Taking A Toll. The New York Times. Retrieved from http://www.nytimes.com/2009/05/26/health/26teen.html?_r=0

Hera. (2008). Hera Live At Al's [MP3 File]. Bandcamp.

------ (2014, September 30). Personal Interview. (n.d.). Hera Sings Bandcamp. Retrieved August 12, 2014 from http://herasings.bandcamp.com

Herald Online. (2013, January 29). Cliff Richard to Wellington: 'Good Evening Auckland'. Retrieved from http://www.nzherald.co.nz/entertainment/news/article.cfm?c_id=1501119\&objectid=1 $\underline{0862058}$

Holt, F. (2007). Genre In Popular Music. Chicago: The University of Chicago Press.

Horn, D., Laing, D., Seed, M., \& Shepherd, J. (Eds.) (2003). Continuum Encyclopedia of Popular Music of the World Volume II: Performance and Production. United Kingdom: Continuum International Publishing Group Ltd.

Huron, D. (2006). Sweet Anticipation: Music and the Psychology of Expectation. Cambridge: Massachusetts Institute of Technology Press. 
Ihde, D. (2007). Listening and Voice: Phenemonologies of Sound. New York: State University of New York Press.

Iser, W. (1978). The Implied Reader: Patterns of Communication in Prose Fiction from Bunyan to Beckett. Baltimore: The Johns Hopkins University Press.

Kivy, P. (1995). Authenticities: Philosophical Reflections on Musical Performance. Ithaca: Cornell University Press.

Krims, A. (2009). Studying Recepton and Scenes. In Scott, Derek B. (Ed.) The Ashgate Research Companion to Popular Musicology (pp. 397-410). Surrey: Ashgate Publishing Limited.

Knopfler, D. (2003, June 18). The Singer-Songwriter: Defining the Genre - Defining the Style. Retrieved from http://www.knopfler.com/articles/songwriters.html

Lankford Jr., R. D. (2010). Women Singer-Songwriters In Rock: A Populist Rebellion in the 1990s. Maryland: Scarecrow Press Inc.

Lanser, S. (2008). The "I" of the Beholder: Equivocal Attachments and the Limits of Structuralist Narratology. In Phelan, James \& Peter J Rabinowitz (Eds.) A Companion to Narrative Theory (pp. 206-219). Massachsetts: Blackwell Publishing Limited.

Laura. (2012, October 16). Nobody Actually Wants a Fucking Martyr: Amanda Palmer \& The Grand Theft Orchestra's "Theatre Is Evil” Reviewed. Retrieved from http://www.fromahighhorse.com/2012/10/16/nobody-actually-wants-a-fuckingmartyr-amanda-palmer-the-grand-theft-orchestras-theatre-is-evil-reviewed/

Little Bastard. (2012, September 13). Theatre Is Evil - Amanda Palmer. In Polari Magarine. Retrieved from http://www.polarimagazine.com/musicreviews/theatre-evilamanda-palmer/

Live Journal. (2010, September 16). 90 Hera Hjartardottir. Retrieved from http://burlesque-show.livejournal.com/180668.html 
McHale, B. (2003). A Poet May Not Exist: Mock-Hoaxes and the Construction of National Identity. In R. J. Griffin (Ed.) The Faces of Anonymity: Anonymous and Pseudonymous Publication from the Sixteenth to the Twentieth Century (pp. 233-252). New York: Palgrave Macmillan.

Middleton, R. (1990). Studying Popular Music. Milton Keynes: Open University Press. (2006). Voicing The Popular: On the Subjects of Popular Music. New York:

Routledge.

Miller-White, M. (2012, December 14). Amanda Palmer Discusses the Power of Social Media. Retrieved from http://www.themountaineer.org/2012/12/amanda-palmer-discussesthe-power-of-social-media/

Ministry of the Interior. (2012, January 22). Information on Icelandic Surnames. Retrieved from http://eng.innanrikisraduneyti.is/information/nr/125

Moore, A. (2001). Categorical Convention in Music Discourse: Style and Genre. Music and Letters 82/3, 432-442. (2002). Authenticity as Authentication. Popular Music 21/2, 209-223.

Morton, K. (2014, July 20). Personal Interview.

Muir, P. (2009). Long Lost Blues: Popular Blues in America, 1850-1920. Urbana: University of Illinois Press.

Palmer, A. (2013, September 1) ${ }^{16}$. The Battle Route for Today's Wellington Ninja Parade. Retrieved from http://amandapalmer.tumblr.com/post/60034784244/the-battle-routefor-todays-wellington-ninja (2014a). The Art of Asking: How I Learned to Stop Worrying and Let Peple Help. New York City: Grand Central Publishing.

${ }^{16}$ Posted September 2nd NZST, but appears as September 1st due to Palmer's Tumblr being set to EDT. 
(2014b, June 24). As a Singer of a Band that People Love to Hate. Retrieved from https://www.facebook.com/amandapalmer/posts/10152292381773375

(2014c, November 10). Maria Popova \& Amanda Palmer on The Art of Askingfull interview. Retrived from https://www.youtube.com/watch?v=u8kSiylePVI (n.d.(a)). Amanda Palmer Bandcamp. Retrieved January 13, 2015 from http://amandapalmer.bandcamp.com/album/who-killed-amanda-palmer (n.d.(b)). Amanda Palmer. In LinkedIn. Retrieved January 13, 2015 from https://www.linkedin.com/in/afpalmer

Powell, A. (2012, September 14). The Naked Authenticity of Amanda Palmer. In The Austin Chronicle. Retrieved from http://www.austinchronicle.com/daily/music/2012-0914/the-naked-authenticity-of-amanda-palmer/

Rebel Circus. (2014, July 23). Amanda Palmer: Punk Cabaret Inspiration. Retrieved from http://www.rebelcircus.com/blog/amanda-palmer/

Richardson, L. (2000). Evaluating Ethnography. Qualitative Inquiry 6, 253-255.

Schechner, R. (1985). Between Theater and Anthropology. Philadelphia: University of Pennsylvania Press.

Smith, G. (2011). The Gendered Voice of Australian Country Music. Context 35/36, 27 38.

Suckling, L. (2009, August 15). Doing the Hard Miles. In Your Weekend. Retrieved from http://leesuckling.com/uploads/2012/06/Hera-Your-Weekend-Aug-16-09.pdf

Tagg, P. (1999). Fernando the Flute. New York: The Mass Media Musicologists' Press. 
Van der Merwe, P. (1989). Origins of the Popular Style: The Antecedents of Twentieth-Century Popular Music. Oxford: Clarendon Press.

Voegelin, S. (2010). Listening To Noise and Silence: Towards a Philosophy of Sound Art. New York: The Continuum International Publishing Group Inc.

Volpi, D. (2012, February 10). Heavy Technology Use Linked to Faitgue, Stress and Depression in Young Adults. The Huffington Post. Retrived from http://www.huffingtonpost.com/david-volpi-md-pc-facs/technologydepression_b_1723625.html

Whiteley, S. (Ed.). (1997). Sexing The Groove: Popular Music and Gender. London: Routeledge.

Wimsatt, W.K. and Beardsley, M. (1954). The Verbal Icon: Studies in the Meaning of Poetry. Kentucky: University of Kentucky Press. 